Materials and Components Technology Division Materials and Components Technology Division Materials and Components Technology Division
Development of a Boron-Copper Neutron Absorber Composite by T. C. Wiencek, H. R. Thresh, and J. R. Summers

Argonne National Laboratory, Argonne, Illinois 60439 
Argonne National Laboratory, with facilities in the states of Illinois and Idaho, is owned by the United States government, and operated by The University of Chicago under the provisions of a contract with the Department of Energy.

\section{DISCLAIMER}

This report was prepared as an account of work sponsored by an agency of the United States Government. Neither the United States Government nor any agency thereof, nor any of their employees, makes any warranty, express or implied, or assumes any legal liability or responsibility for the accuracy, completeness, or usefulness of any information, apparatus, product, or process disclosed, or represents that its use would not infringe privately owned rights. Reference herein to any specific commercial product, process, or service by trade name, trademark, manufacturer, or otherwise, does not necessarily constitute or imply its endorsement, recommendation, or favoring by the United States Government or any agency thereof. The views and opinions of authors expressed herein do not necessarily state or reflect those of the United States Government or any agency thereof.

Reproduced from the best available copy.

Available to DOE and DOE contractors from the

Office of Scientific and Technical Information

P.O. Box 62

Oak Ridge, TN 37831

Prices available from (615) 576-8401, FTS 626-8401

Available to the public from the

National Technical Information Service

U.S. Department of Commerce

5285 Port Royal Road

Springfield, VA 22161 


\title{
DEVELOPMENT OF A BORON-COPPER NEUTRON
} ABSORBER COMPOSITE

\author{
by
}

T. C. Wiencek, H. R. Thresh, and J. R. Summers

Materials and Components Technology Division Mechanics of Materials Section

May 1991

Work sponsored by

U.S. DEPARTMENT OF ENERGY

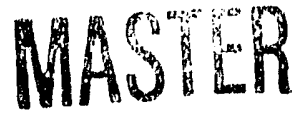
Basic Energy Sciences-Material Science 


\section{Contents}

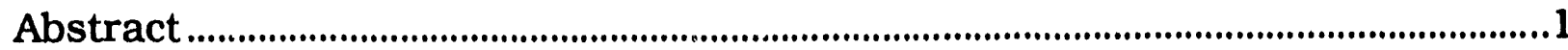

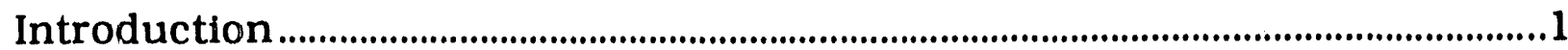

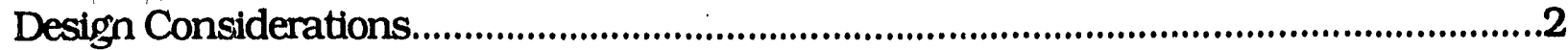

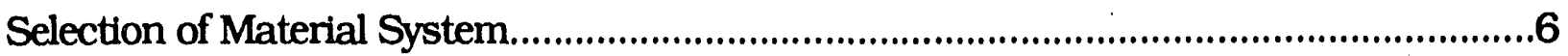

Materials Characterization and Processing..................................................................7

Production of Flat Copper-Clad 10B-Cu Stock Plates.......................................11

Characterization and Inspection of Stock ${ }^{10} \mathrm{~B}-\mathrm{Cu}$ Plate Material....................14

Machining, Roll-Forming, and Assembly of Stock ${ }^{10} \mathrm{~B}-\mathrm{Cu}$ Plates

into Finished Hardware.........................................................................................................25

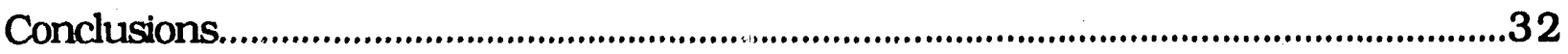

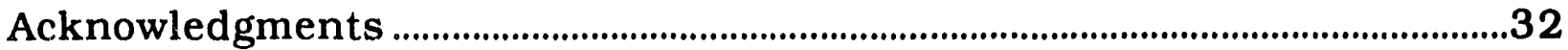

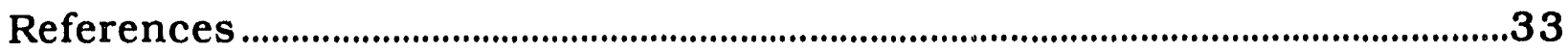

\section{List of Figures}

1 Internal spring support decoupler insert of IPNS booster.........................3

2 Target housing decoupler insert of IPNS booster ................................................

$3{ }^{10} \mathrm{~B}-\mathrm{Cu}$ pieces of target proton beam decoupler in IPNS booster.............4

$4{ }^{10} \mathrm{~B}-\mathrm{Cu}$ pieces of target bore tube decoupler in IPNS booster..................4

5 Booster target installed in moderator/reflector assembly ..........................5

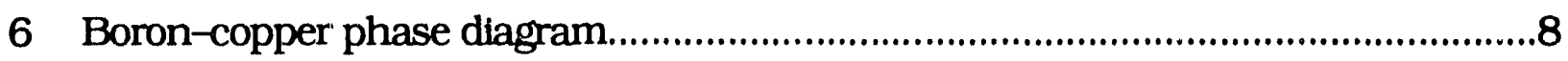

7 Cross section (macro and micro) of typical plate of ${ }^{10} \mathrm{~B}-\mathrm{Cu}$ composite.. 


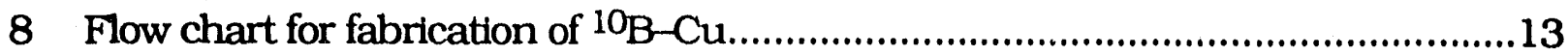

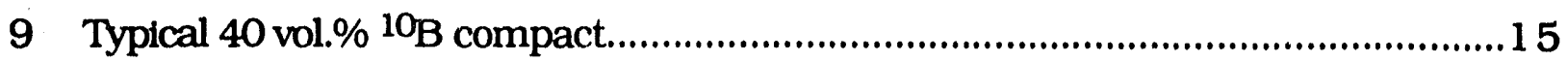

10 Copper frame and cover plate for cladding of ${ }^{10} \mathrm{~B}-\mathrm{Cu}$ compact.................15

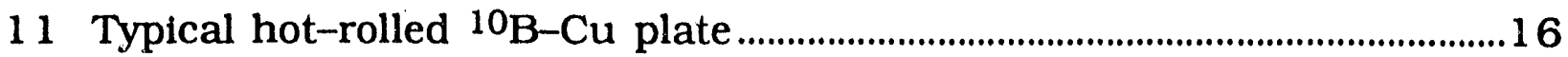

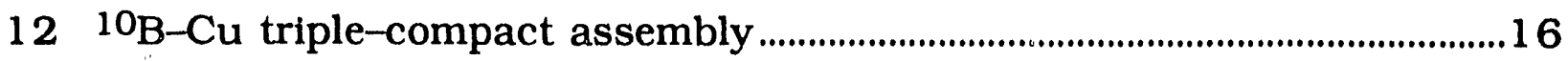

13 Hot-rolled triple-compact plate of $10_{\mathrm{B}-\mathrm{Cu}}$ with copper cladding

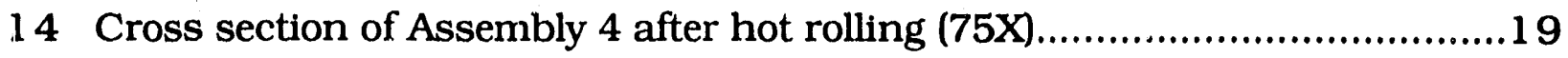

15 Cross section of Assembly 4 after hot rolling (500X) .................................19

16 Sample of Assembly 1 after heat treatment in air for $7 \mathrm{~h}$ at $895^{\circ} \mathrm{C}$

17 Sample of Assembly 1 after heat treatment in air and cleaning ...............24

18 Metallographic sample of Assembly 1 after $7 \mathrm{~h}$ at $900^{\circ} \mathrm{C}$ and protection from severe exposure to air

19 Finished internal spring support decoupler insert, Side A.........................27

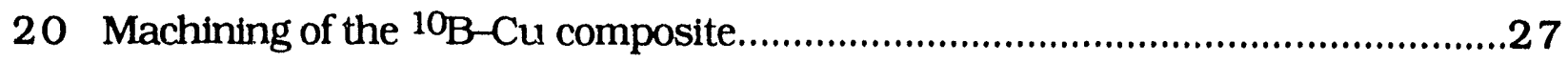

21 Finished IPNS booster target housing decoupler insert .............................28

22 Assembly of IPNS booster target tube decoupler ...........................................29

23 Finished IPNS proton beam tube decoupler assembly ................................30

24 Fabrication of IPNS booster target tube decoupler .......................................... 31

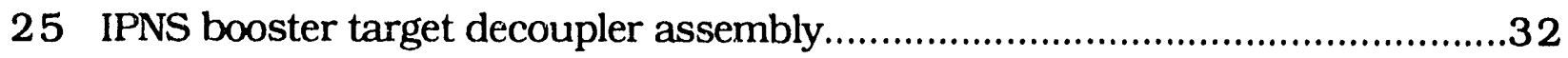




\section{List of Tables}

1 Chemical composition of \#C10100 copper sheet............................................9

2 Chemical composition of Alcan 185E copper powder .......................................9

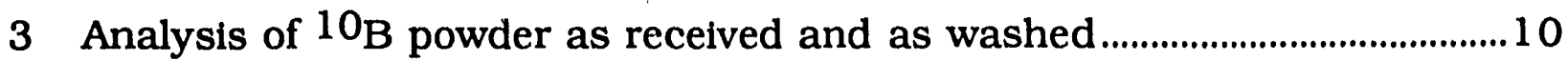

4 Fabrication and final use of ${ }^{10} \mathrm{~B}-\mathrm{Cu}$ assemblies .................................................. 12

5 Effect of fabrication technique on percent porosity in meat.........................18

6 Measurement of $10_{\mathrm{B}}$ loadings ........................................................................22

7 Comparison of booster target $10_{\mathrm{B}}$ atom area densities determined by various methods ...................................................................................23

8 Results of time-at-temperature tests ............................................................23 
This report describes the fabrication of a new boron-copper neutron absorbing material that was developed to meet the upgrading needs of the Intense Pulsed Neutron Source (IPNS) at Argonne National Laboratory. To increase the intensity of the neutron beams from the IPNS, the target uranium was changed from depleted uranium to uranium enriched to $\mathbf{7 7 . 5 \%}$ 235U. To keep the multiplication factor, $k_{\text {eff }}$ (number of fissions in one generation/number of fissions in preceding generation) at a safe level, a new neutron absorber material was needed. The previous materials, boral and cadmium, could not meet the new requirements and a search of the literature showed that no currently available material was acceptable. With previous powder metallurgy used as a base, the composite was fabricated with 43 vol.\% ${ }^{10} \mathrm{~B}\left(81 \%\right.$ enriched $\left.{ }^{10} \mathrm{~B}\right)$ and the balance copper and voids. The powder metallurgy technique was followed by hot-rolling the composite to a sheet. The material, composed of boron particles dispersed in a pure copper matrix and clad with pure copper on both sides, exhibits the following properties:

- Loadings up to 43 vol.\% boron, with the balance copper and voids.

- A loading of $0.5 \times 10^{22} 10 \mathrm{~B}$ atoms $/ \mathrm{cm}^{2}$ in sections as thin as 0.067 in. $(1.7 \mathrm{~mm})$, with copper cladding as thin as $0.010 \mathrm{in} .(0.25 \mathrm{~mm})$.

- Formability to radii as small as $2.1 \mathrm{in}$. $(53.3 \mathrm{~mm})$.

- No observed reaction between boron and the copper matrix and cladding at temperatures up to $900^{\circ} \mathrm{C}$ for times as long as $7 \mathrm{~h}$.

- Retains structural integrity at $900^{\circ} \mathrm{C}$.

\section{Introduction}

The Intense Pulsed Neutron Source (IPNS) at Argonne National Laboratory (ANL) is a spallation neutron source. The interaction between a pulsed beam of protons and a heavy metal target produces a spallation process that generates a neutron source. Since startup in 1981, the original design has operated with a target assembly containing eight target discs. 1 Each target disc consists of a depleted uranium core encapsuled in a bonded clad of Zircaloy-2. The target and its cooling and monitoring systems have operated very reliably and safely. However, beam parameters and target 
density limit the maximum neutron yield from the spallation process. A design modification that increases the maximum yield of neutrons by a factor of approximately 3 has been approved. The modification includes the use of enriched uranium (77.5\%) in a new target assembly containing 13 uranium cores clad with Zircaloy-2. This new target assembly is referred to as the booster upgrade assembly. The neutron yield from the new target assembly will provide a spallation reaction augmented by fissioning of the target ${ }^{235} \mathrm{U}$. This approach requires control of the thermal portion of the neutron spectrum to keep the multiplication factor, $\mathrm{k}_{\mathrm{eff}}$ (number of fissions in one generation/number of fissions in preceding generation) below 0.85 .

For the IPNS booster upgrade, a neutron absorber was required for the confined areas of the target assembly zone. To keep $\mathbf{k}_{\mathrm{eff}}$ at a safe level, three specific zones required neutron absorber material: the back disc of the target pressure housing assembly, the liner of the proton tube decoupler, and the liner of the target decoupler. This report discusses the design, fabrication, and final assembly issues in ensuring that the IPNS booster design meets the specified engineering goals.

\section{Design Considerations}

Shielding material of four different shapes was required for the upgraded IPNS. Engineering requirements were specified in the following drawings: N4100-0090-DB Internal Spring Support Decoupler Insert (Fig. 1), N4100-0086-DB Target Housing Decoupler Insert (Fig. 2), N42000233-DB Proton Beam Tube Decoupler (Fig. 3) and N4200-0235-DB Bore Tube Decoupler (Fig. 4). The assembly drawing, Fig. 5, shows the location, general dimensions, and shape of the required absorber material.

The physics calculations (e.g., keff, energy deposition, neutron yield) for the booster target assumed a $10 \mathrm{~B}$ atom area density of $1 \times 10^{22} 10^{10}$ atoms $/ \mathrm{cm}^{2}$ for all locations except the vessel walls. Assumed density in the vessel walls was $0.5 \times 10^{22} 10 \mathrm{~B}$ atoms $/ \mathrm{cm}^{2}$. During fabrication of the ${ }^{10} \mathrm{~B}-\mathrm{Cu}$ decoupler material, these assumptions were treated as minimal ${ }^{10} \mathrm{~B}$ atom area density goals.

Further requirements of the undefined shielding material were:

- A loading of $0.5 \times 10^{22} 10^{\mathrm{B}}$ atoms $/ \mathrm{cm}^{2}$ in sections as thin as 0.065 in. and undefined cladding as thin as $0.010 \mathrm{in}$. 


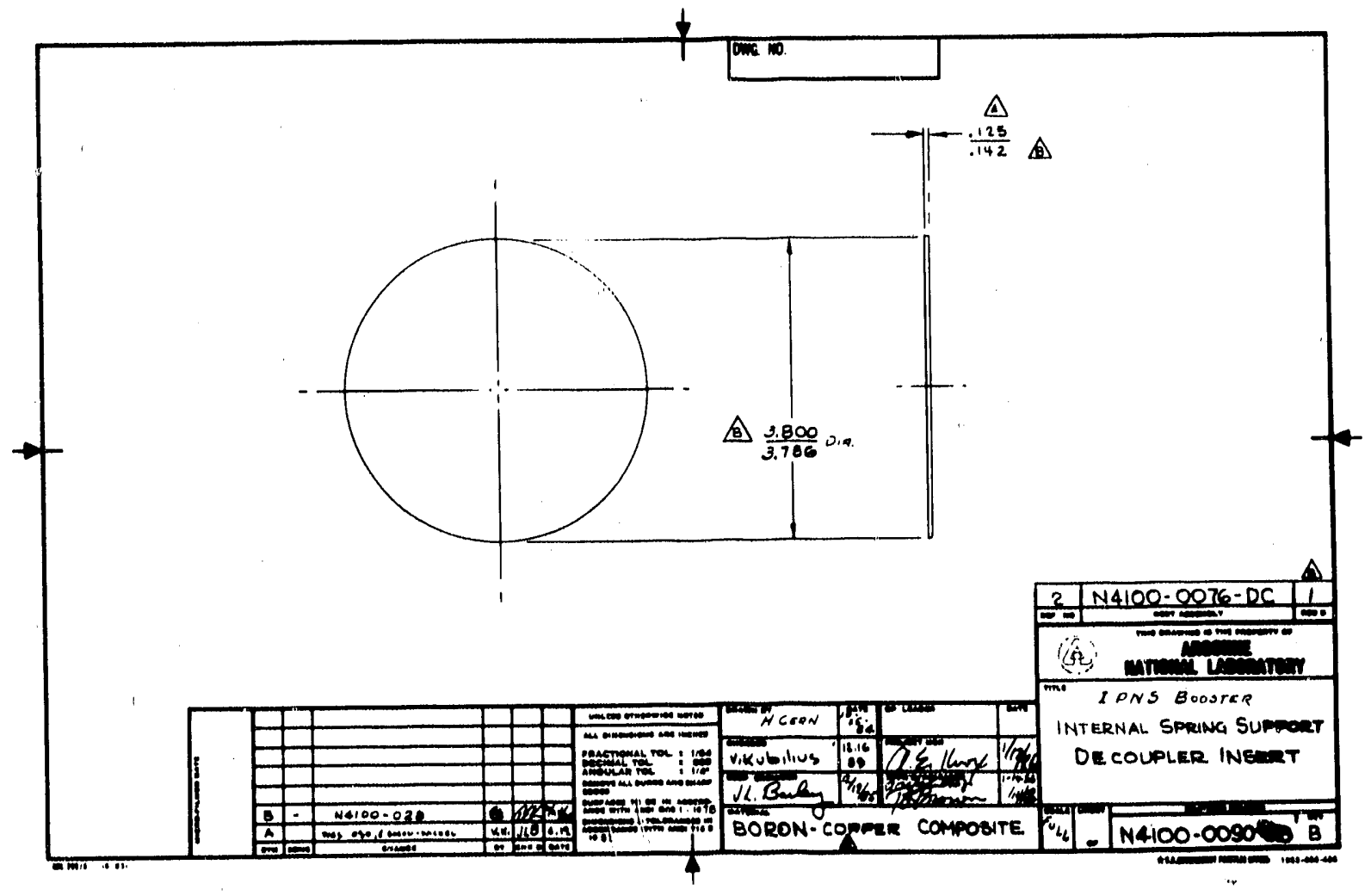

Fig. 1. Internal spring support decoupler insert of IPNS booster

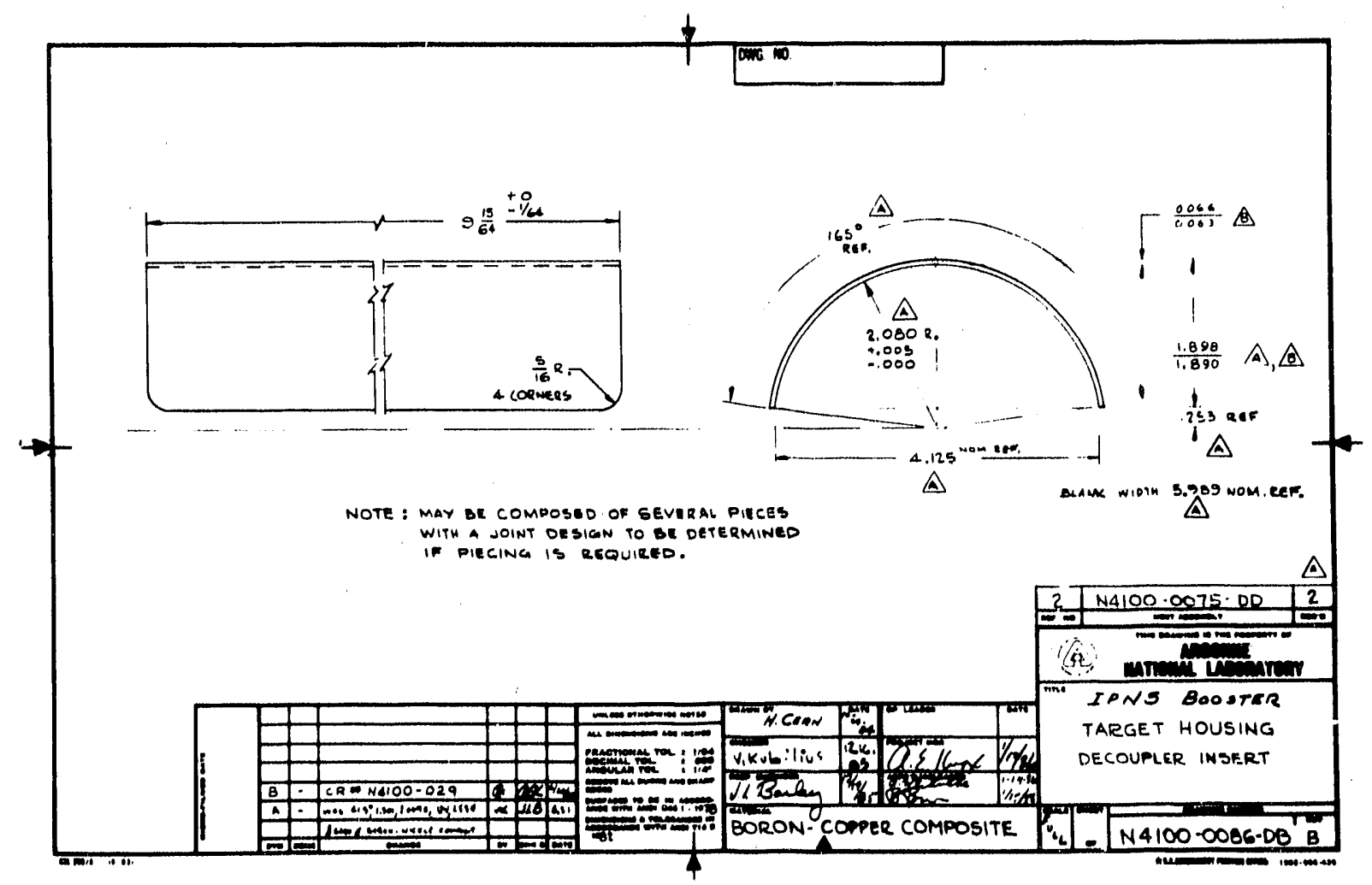

Fig. 2. Target housing decoupler insert of IPNS booster 


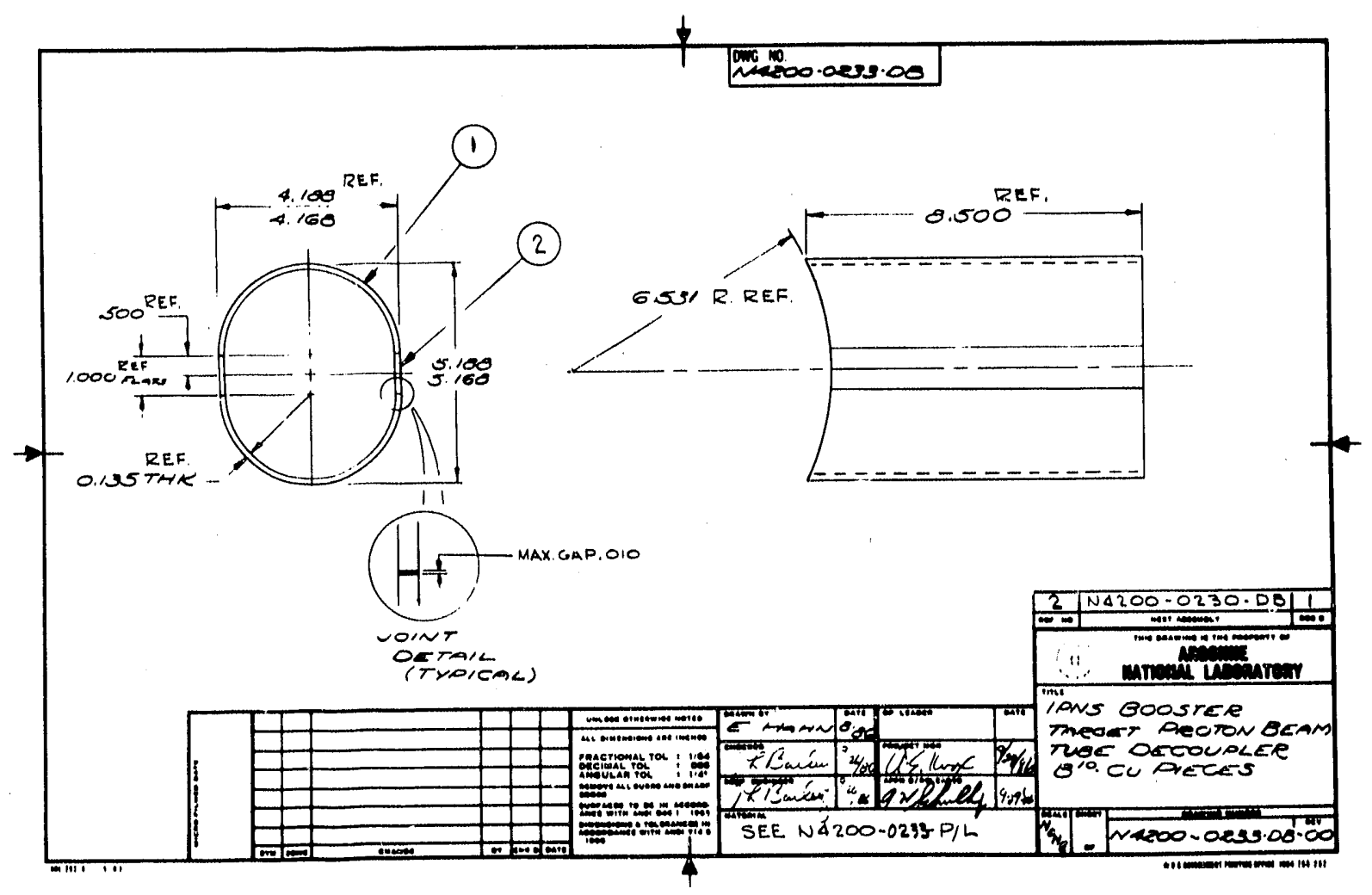

Fig. 3. ${ }^{10} B-C u$ pieces of target proton beam decoupler in IPNS booster

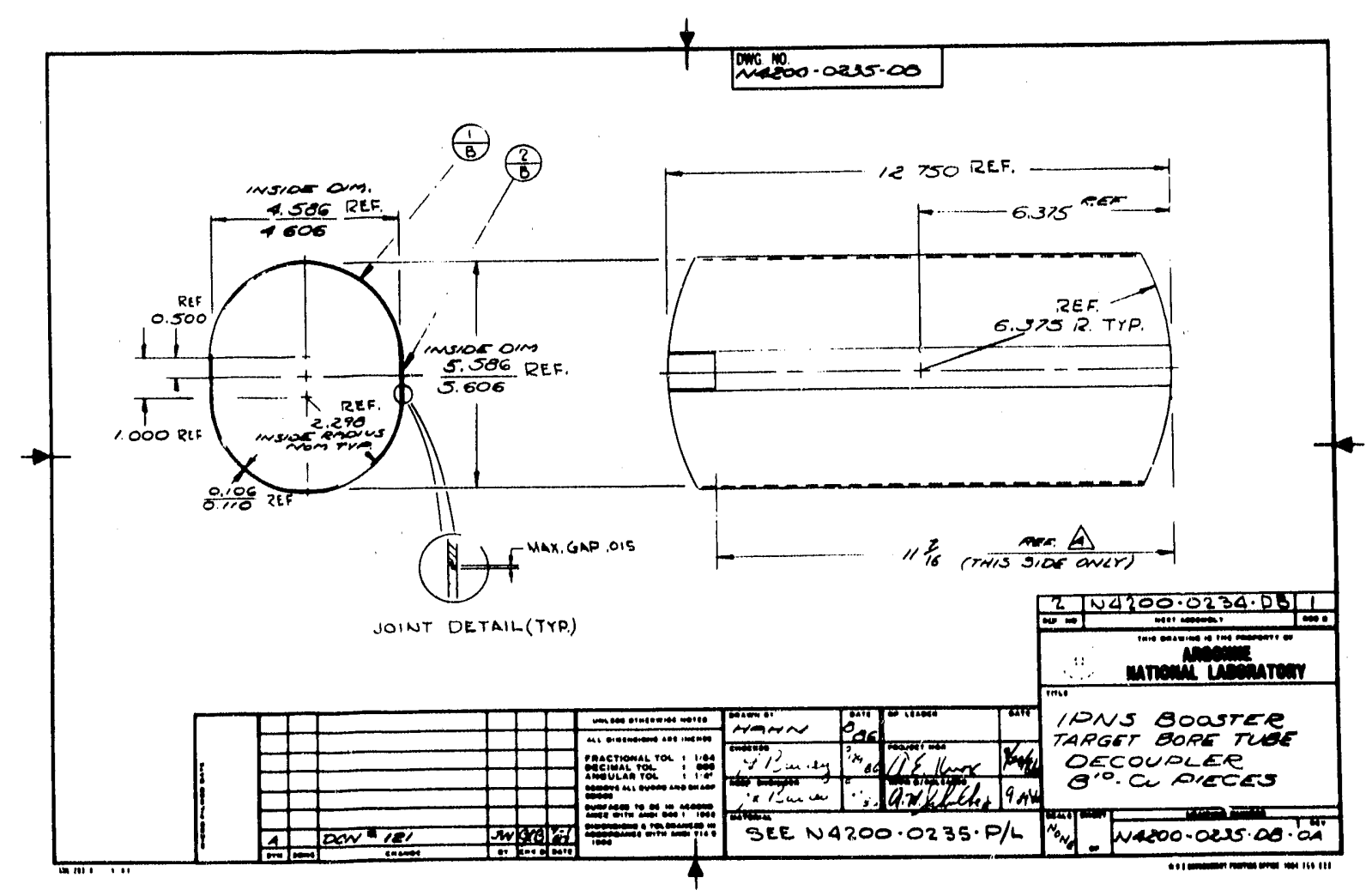

Fig. 4. ${ }^{10} \mathrm{~B}-\mathrm{Cu}$ pieces of target bore tube decoupler in IPNS booster 


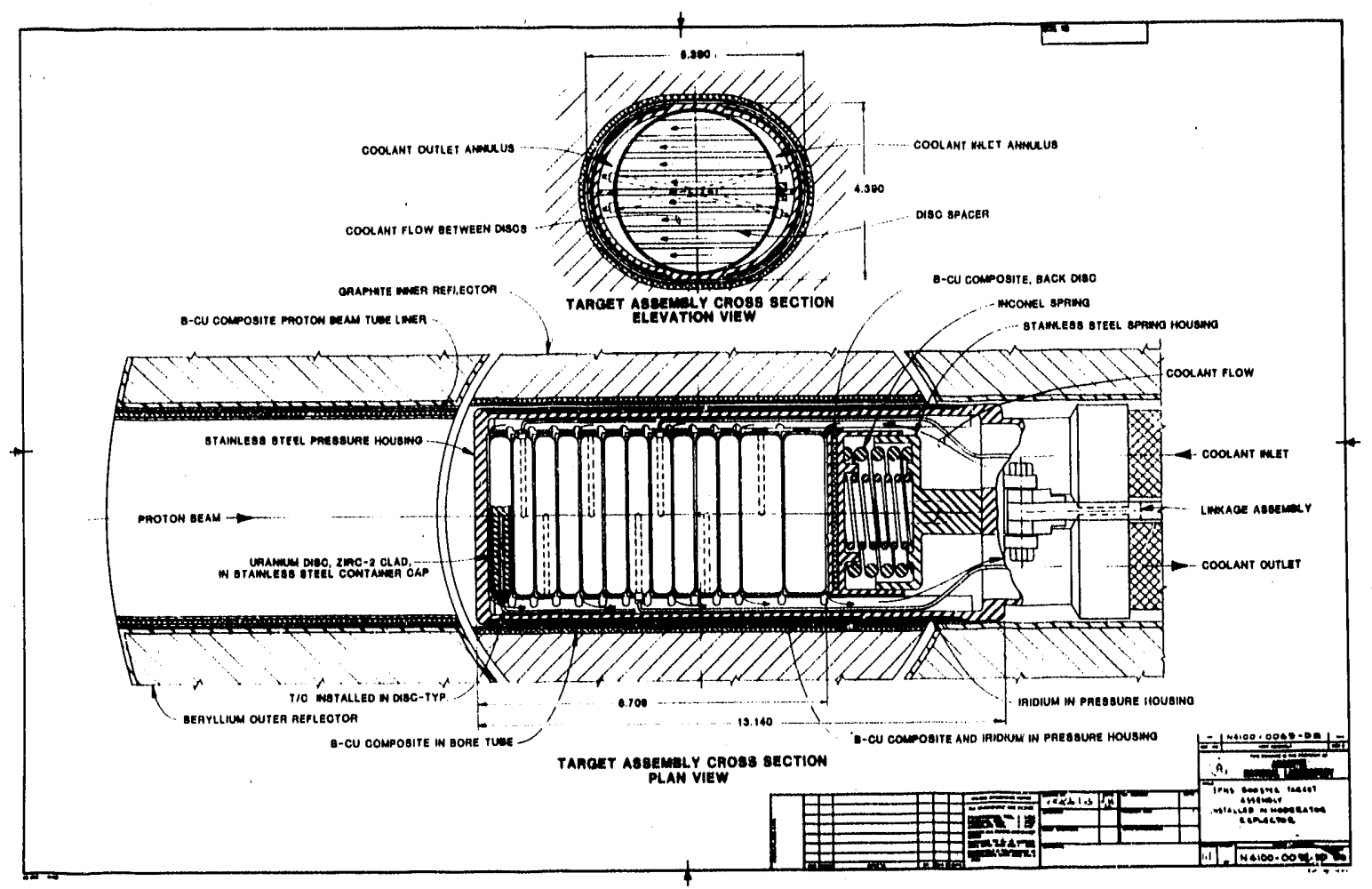

Fig 5. Booster target installed in moderator/reflector assembly

- A loading of $1.0 \times 10^{22} 10^{\mathrm{B}}$ atoms $/ \mathrm{cm}^{2}$ in sections as thin as 0.110 in. and undefined cladding as thin as $0.010 \mathrm{in}$.

- Formability to radii as small as 2.1 in.

- No observed reaction between the boron and its matrix at temperatures up to $900^{\circ} \mathrm{C}$ over times as long as $7 \mathrm{~h}$.

- Retention of structural integrity at $900^{\circ} \mathrm{C}$.

These criteria could not be met with currently available shielding materials such as cadmium or boral (boron carbide in an aluminum matrix). A literature search ${ }^{2-5}$ disclosed that no currently available material was acceptable. Conventional techniques, such as that of Worn et al., 6 have been based on the fact that higher concentrations of boron cause severe embrittlement of composite structures. Thus, high boron concentration causes poor ductility and consequent problems in bending and shaping currently available materials. It was therefore required to develop a new material with increased capacity for neutron absorption, structural integrity 
in the face of high temperatures that would melt or damage current materials, and ductility that would allow the manufacture of thin formed shapes.

\section{Selection of Material System}

Before the boron was selected, the boron carrier compound and the matrix that would be used, as well as the current limit of dispersion fabrication technology, required defining. The involvement of the ANL Fabrication Technology Section* with a previous program 7 led to expertise in the fabrication of clad dispersion fuel plates that contain uranium-bearing silicide cornpounds dispersed in an aluminum matrix clad with a bonded layer of 6061 aluminum alloy. The hard, brittle silicide was synthesized by taking advantage of the soft, ductile nature of aluminum to press it into a densified compact by powder metallurgy methods. After the compact was enclosed in a heavy-wall picture frame and covers of aluminum alloy, and the outer edges welded together, a hot-rolling operation developed a sheetform geometry along with a bonded outer clad. Densification reached the point where a residual porosity of $11-15 \%$ was typical. This is the current state of the art for highly loaded, dispersion-type fuel plates; the method is limited to loadings of 50 vol.\%. Similar needs were evident for the shielding material. Production of shielding plates required the fabrication boron (a hard material) in a soft matrix. Experience indicated that the shielding material could be fabricated by a variation of the method used for the fuel plates.

The choice of the boron-bearing material was relatively straightforward. Assuming a 50 vol.\% loading limit for boron dispersion, all forms of natural boron were eliminated because of insufficient $10 \mathrm{~B}$ loading. To conform to loading requirements, it would be necessary to use an enriched boron. Even with enriched boron, the ${ }^{10} \mathrm{~B}$ density of the common boron compounds $\mathrm{B}_{4} \mathrm{C}$ and BN was not high enough. Thus, the boron source was limited to enriched elemental boron. With the design loading of $1.0 \times 10^{22} 10 \mathrm{~B}$ atoms $/ \mathrm{cm}^{2}$ or $0.5 \times 10^{22} 10 \mathrm{~B}$ atoms $/ \mathrm{cm}^{2}$, a boron enrichment of $90 \%$, a boron purity of $90 \%$, and the required thicknesses, the minimum necessary boron loading in the finished product was 34 vol.\% boron. For safety, the target loading was set at $40 \%$ boron.

"Now part of the Mechanics of Materials Section. 
The matrix material was limited to pure metals that were available as powder and had a melting point above $900^{\circ} \mathrm{C}$. Pure metals were chosen because they have maximum ductility. The selected metal could not be activated easily by the neutron flux. These requirements eliminated aluminum because of temperature constraints and cobalt because of activation constraints. Nickel, iron, and copper were chosen as possible matrix materials. A few trial plates were fabricated with nickel as the matrix, but were not successful. This could be clue to the many line compounds in the B-Ni system, which could cause poor compatibility. Iron was eliminated for the same reason. The B-Cu system (see Fig. 6), which has no line compounds, was finally chosen as the matrix material after preliminary test plates were rolled successfully.

The process design centered on synthesizing hard, enriched ${ }^{10} \mathrm{~B}$ particles with soft copper particles to form a composite structure clad with an outer layer of copper. A typical schematic cross section of the material is shown in Fig. 7 . When a previously developed technique ${ }^{7}$ was applied to the B-Cu system, a flat plate was the primary fabrication shape. For ease of fabrication, a standard size was established for compacts. One compact was then hot-rnlled into the plate configuration as shown in Fig. 7. Larger monolithic plates were formed by hot-rolling two and/or three compacts as a unit. The plates were then arc-shaped by roll-forming.

\section{Materials Characterization and Processing}

The hardware composite consisted of copper sheet, copper powder, and boron powder. The copper sheet was commercially available OFE 99.99 wt.\% copper UN.S \#C10100, with the chemical composition listed in Table 1. The copper powder was Alcan $185 \mathrm{E}$ with a $12-\mu \mathrm{m}$ average particle size. Table 2 gives a typical analysis of this powder.

Both the copper sheet and the copper powder were chosen for their ease of fabrication and their boron compatibilicy.

The boron powdier (from U.S. Borax) was analyzed in the as-received condition; results are summarized in Table 3. Because the material was relatively impure and because it was necessary 10 maximize the boron content (and keep it to less than 50 vol.\% in the final hardware), a method 


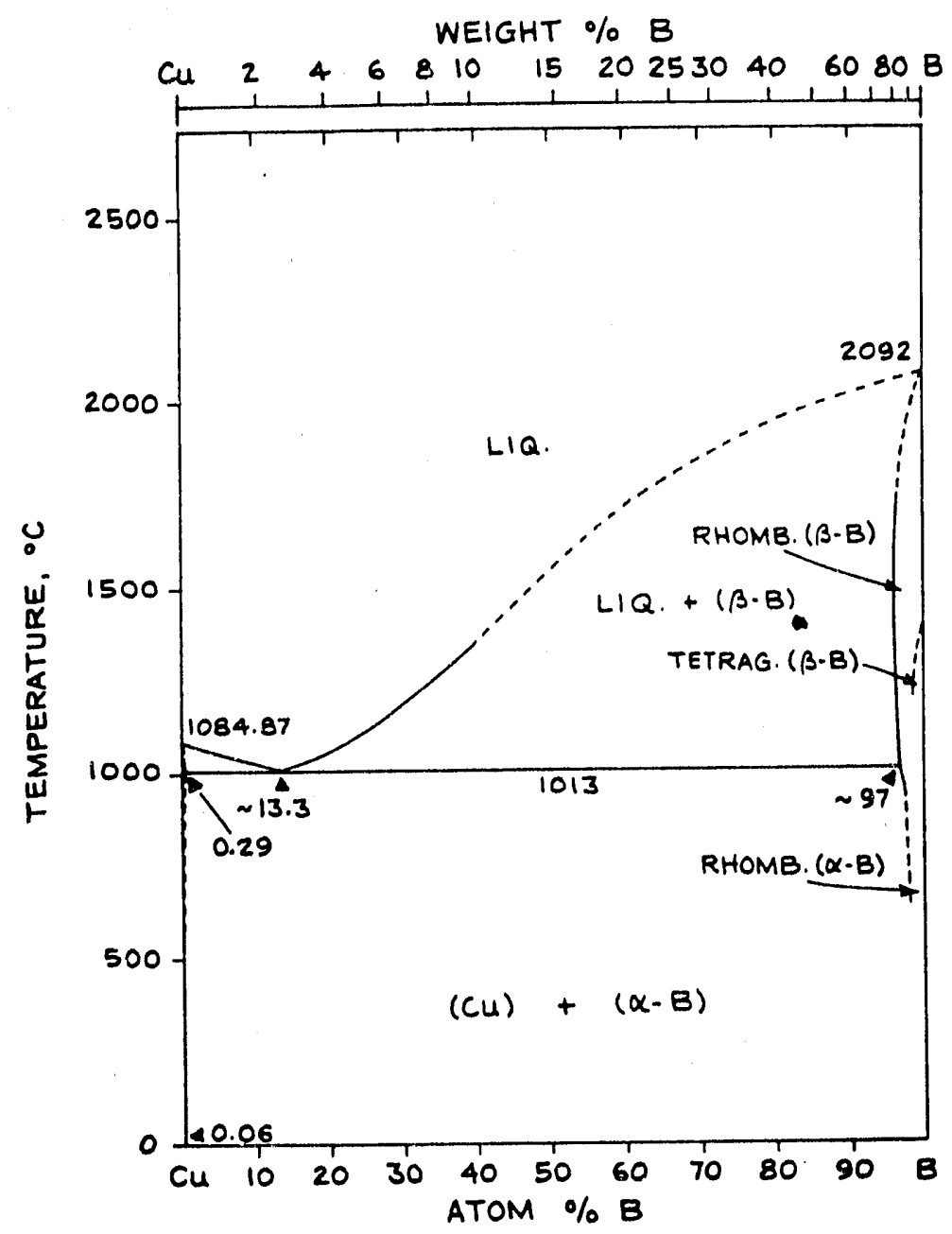

Fig. 6. Boron-copper phase diagram

was devised to increase the elemental boron content of the powder.

Analysis revealed that the main impurity was silicon. Although oxygen was not analyzed, boron oxide is known to form on boron under ambient conditions. Because the material had been stored in air for a long period, it was assumed that oxdde contamination was present. Inasmuch as boron oxide is soluble in methyl alcohol, the production boron powder was then "washed" in methanol and vacuum-dried. The results (Table 3) show that this procedure improved the purity of the material. A small sample was washed by the ANL Analytical Chemistry Laboratory and the results are included for comparison. All production hardware was fabricated with washed ${ }^{10} \mathrm{~B}$ powder. 
Table 1. Chemical composition of \#C10100 copper sheet

\begin{tabular}{lr}
\hline Component & $\begin{array}{c}\text { Composition } \\
\text { (wt.\%)a }\end{array}$ \\
\hline $\mathrm{Cu}$ & 99.9900 \\
$\mathrm{P}$ & 0.0003 \\
$\mathrm{~S}$ & 0.0015 \\
$\mathrm{Zn}$ & 0.0001 \\
$\mathrm{Cd}$ & 0.0001 \\
$\mathrm{O}$ & 0.0005 \\
$\mathrm{Hg}$ & 0.0001 \\
$\mathrm{Bi}, \mathrm{Pb}$, Se, T (each) & 0.0010 \\
$\mathrm{Bi}, \mathrm{Sn}, \mathrm{Mn}, \mathrm{Sb}$, As, Se, Te (total) & 0.0040 \\
No single impurity exceeds & 0.0025 \\
\hline
\end{tabular}

avalue for $\mathrm{Cu}$ is minimum; all other values are maximums.

Table 2. Chemical composition of Alcan 185E copper powder

\begin{tabular}{lc}
\hline Component & $\begin{array}{c}\text { Composition } \\
\text { (wt.\%) }\end{array}$ \\
\hline $\mathrm{Cu}$ & 99.7 \\
$\mathrm{Fe}$ & 0.0064 \\
$\mathrm{Sn}$ & 0.0288 \\
$\mathrm{Ni}$ & 0.0009 \\
$\mathrm{~Pb}$ & 0.004 \\
$\mathrm{Mn}$ & 0.0002 \\
$\mathrm{C}$ & 0.0100 \\
$\mathrm{Zn}$ & 0.0026 \\
$\mathrm{H}$ & loss \\
(surface oxidation) & 0.15 \\
\hline
\end{tabular}




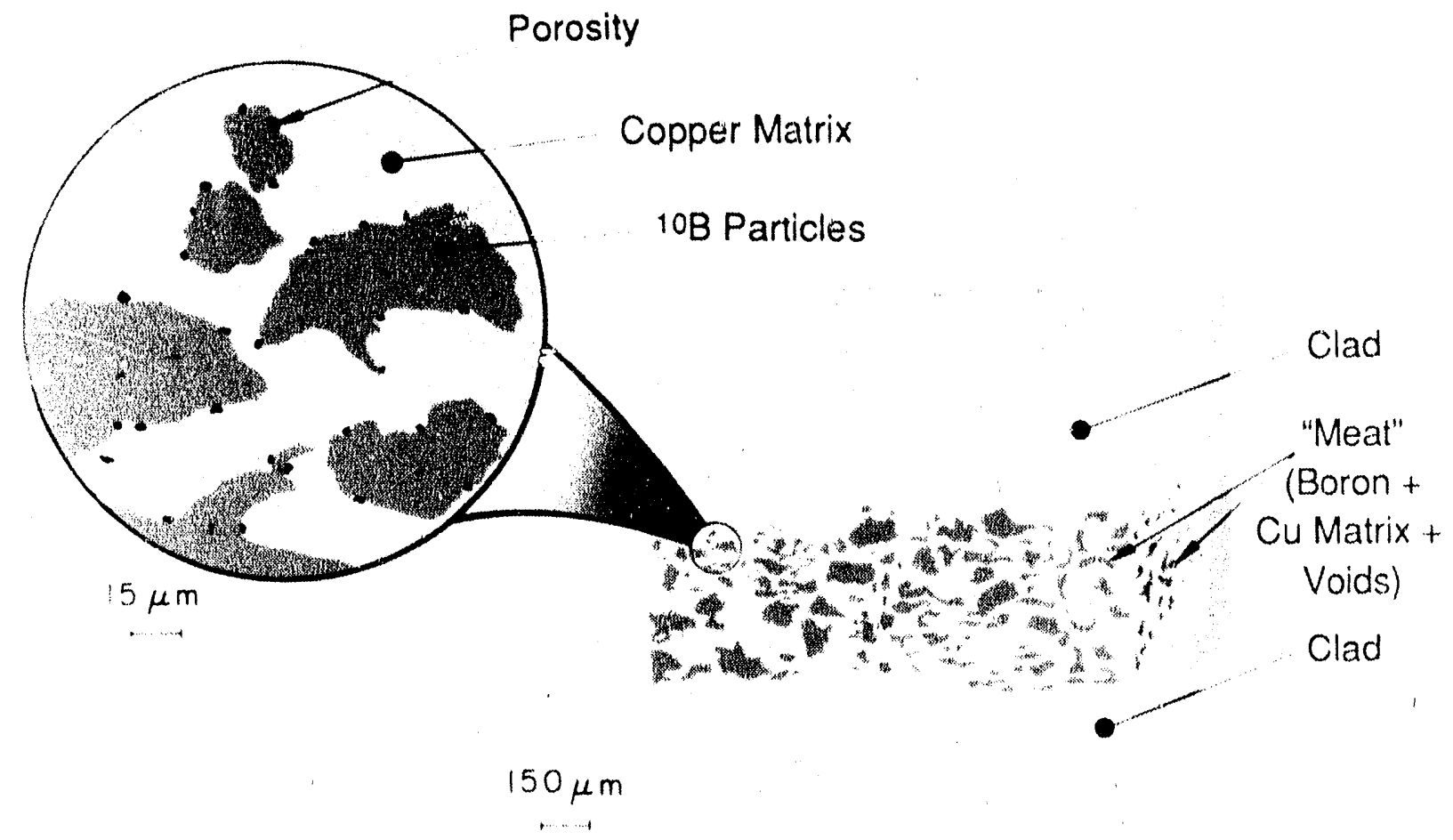

Fig. 7. Cross section (macro and micro) of typical plate of $10_{B-C u}$ composite Table 3. Analysis of ${ }^{10_{B}}$ powder as received and as washed

\begin{tabular}{llrr}
\hline & & \multicolumn{2}{c}{ As Washed } \\
\cline { 3 - 4 } Material & As Received & $\begin{array}{c}\text { Production } \\
\text { Powder }\end{array}$ & $\begin{array}{r}\text { By Analytical } \\
\text { Chemistry Lab. }\end{array}$ \\
\hline $10 \mathrm{~B}$ & $89.77 \pm 0.05$ & $90.29 \pm 0.05$ & $90.29 \pm 0.05$ \\
$1 \mathrm{~B}^{\mathrm{B}}$ & $10.23 \pm 0.05$ & $9.71 \pm 0.05$ & $9.71 \pm 0.05$ \\
Total Boron $^{\mathrm{b}}$ & $85.3 \pm 0.25$ & $89.7 \pm 0.08$ & $89.25 \pm 0.25$
\end{tabular}

avalues given are wt.\% of total boron.

b Balance of $\mathrm{B}$ powder is $1-10 \mathrm{wt} . \% \mathrm{Si}, 1.6 \mathrm{wt} . \%$ total $\mathrm{Al}$, $\mathrm{Ca}, \mathrm{Cr}, \mathrm{Cu}, \mathrm{Fe}, \mathrm{K}, \mathrm{Mg}, \mathrm{Mn}, \mathrm{Na}, \mathrm{Ni}$, and $\mathrm{Pb}$. 


\section{Production of Flat Copper-Clad 10B-Cu Stock Plates}

Table 4 summarizes the fabrication and final use of the stock material produced for the IPNS upgrade. Thirteen ${ }^{10} \mathrm{~B}-\mathrm{Cu}$ assemblies were fabricated from the stock plates. The first three assemblies, ${ }^{10} \mathrm{~B}-\mathrm{Cu} 1-3$. were used in developing the process for fabricating an acceptable product: the homogeneity of the meat and the uniformity of the clad thickness were studied and developed. Assemblies ${ }^{10} \mathrm{~B}-\mathrm{Cu}$ 4-13 were fabricated into the

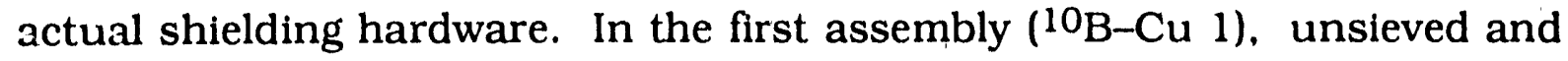
as-received boron powder was mixed with copper powder, compacted, clad, and rolled according to a previously developed hot-rolling schedule. ${ }^{7}$ A reduction of $25 \%$ was achieved during passes 1 and 2; passes 3 and up yielded a $20 \%$ reduction. Assembly ${ }^{10} \mathrm{~B}-\mathrm{Cu} 1$ was also used to determine if the copper would react with the boron during the hot-rolling. Although the sample yielded useful rolling information, it was very inhomogeneous and had a very uneven surface finish that was caused by severe oxidation during rolling at $900^{\circ} \mathrm{C}$. Sieved and washed powder was thus determined as much more representative of the actual final product.

Based on this determination, the second assembly was fabricated from sieved and washed powder according to a toot-and cold-rolling schedule (see Table 4). The final rolling passes were made at room temperature in an attempt to improve the surface finish. Boron distribution was noticeably improved. Because some shield plates required an arc shape, a section of the second assembly was roll-formed in a single pass to a 2 -in. radius.

Some cracking was evident after this operation. A second piece was formed by using three smaller roll-forming passes. Between passes, the sample was annealed. This method resulted in a satisfactory curved plate and was later used in forming the production plates.

Generally, the overall quality of the plate could be improved by eliminating the cold-rolling and finding another method to improve the surface finish. Experience had shown that cold-rolling increases the porosity of a dispersion-type plate. To stop the oxidation that caused the uneven surface finish, the plate was double-covered in stainless steel foil wrap before hot-rolling. The third covered assembly was hot-rolled to final size; it exhibited the best homogeneity of the test plates. From these test pieces, a fabrication flow chart was developed. It evolved during production and is shown in its final form in Fig. 8. 


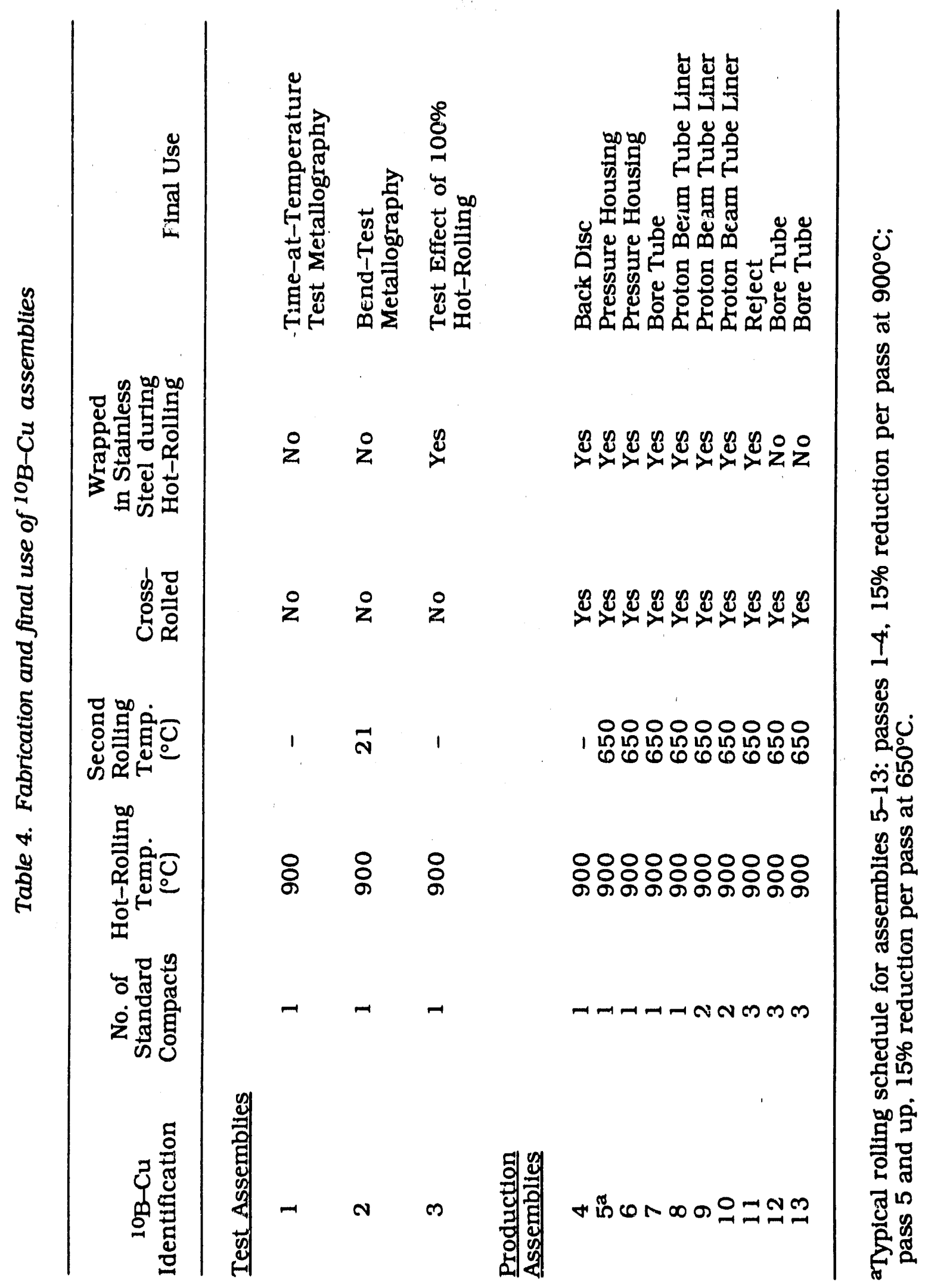




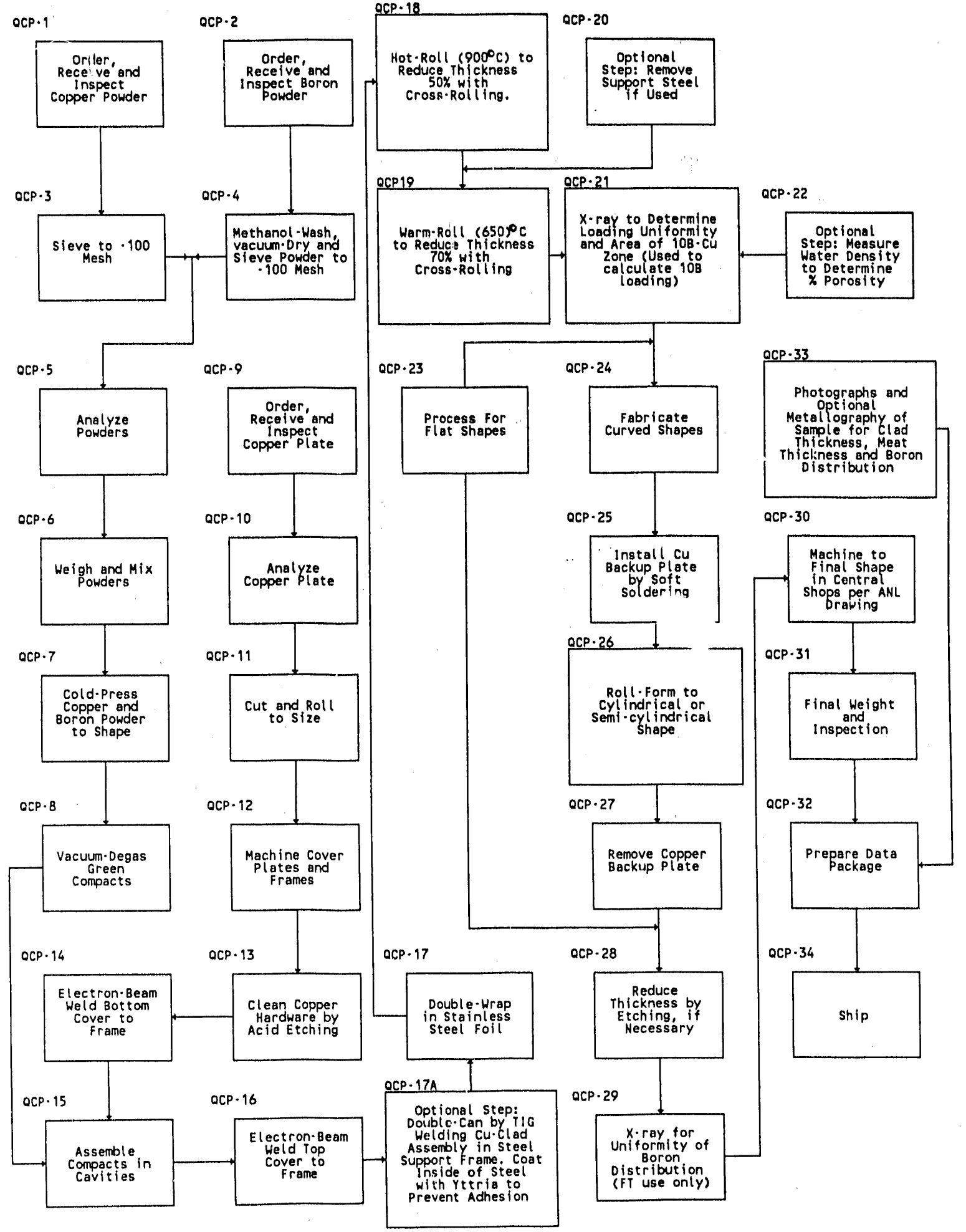

Fig. 8. Flow chart for fabrication of ${ }^{10} \mathrm{~B}-\mathrm{Cu}$ 
To summarize the process, a 4.0 vol.\% $10 \mathrm{~B}$ compact (balance copper and void) $=2.5$ in. $x 2.5$ in., was cold-pressed and vacuum-annealed before assembly. A typical compact is shown in Fig. 9. A nominally pure copper cover plate and frame (Fig. 10) were cleaned by etching, assembled, electron-beam welded (typical welding parameters: $140 \mathrm{kV}, 3.0 \mathrm{~mA}, 20$ in./min travel speed, and sharp focus) and hot-rolled $\approx 80 \%$ in several rolling passes. A typical as-hot-rolled plate was cleaned after rolling and is illustrated in Fig. 11. For plates of larger areas, the concept was expanded to two or three ${ }^{10} \mathrm{~B}-\mathrm{Cu}$ compact assemblies.

Assembly 11 was the first triple-compact assembly to be rolled. The distribution $\mathrm{X}$-rays showed that the final meat ( $\mathrm{B}+\mathrm{Cu}$ matrix and voids) homogeneity was much poorer than that of previous assemblies. Study of the meat-distribution shape revealed a pattern: the areas of least restraint were poorest in quality. As the frame shape changed from square to rectangular, the problem increased. To constrain the copper frame, a second can made of 1 -in. steel was placed around the assembly before rolling. This method, used for assemblies 12 and 13, reduced the problem of inhomogeneity in the larger plates.

Figure 12 shows a triple-compact assembly before welding. The three ${ }_{10} \mathrm{~B}-\mathrm{Cu}$ compacts are surrounded by a copper frame. Two copper spacer slugs are inserted above and below the compact, and the top and bottom covers were welded on by the electron-beam technique. The resulting hotrolled plate is shown in Fig. 13. A monolithic ${ }^{10} \mathrm{~B}-\mathrm{Cu}$ shield up to $1 \mathrm{ft}^{2}$ was fabricated by this method.

\section{Characterization and Inspection of Stock $10 \mathrm{~B}-\mathrm{Cu}$ Plate Material}

To determine the boron loadings of the as-rolled plates, the density of seven of the first eight plates was measured by the Archimedes principle; results are given in Table 5. Due to their size and weight, plates 9-13 were not measured this way. The first assembly was hot-rolled at $900^{\circ} \mathrm{C}$ but not cross-rolled. The result was a 35 vol.\% boron loading with a 21 vol. \% void. In a effort to attain the target loading of 40 vol.\% boron, the total boron was increased in plate 2. Also, to improve the surface finish, the sample was cold-rolled $\approx 50 \%$. Boron increased to 38 vol. $\%$, but porosity also increased, to $26 \mathrm{vol. \%}$. For the fourth assembly, the plate was hot-rolled to size and 


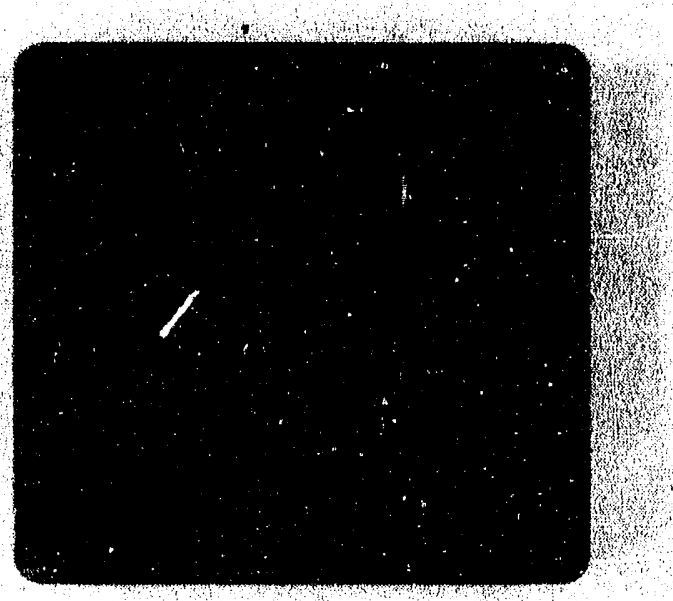

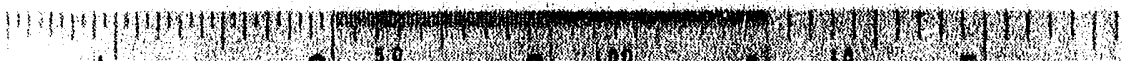

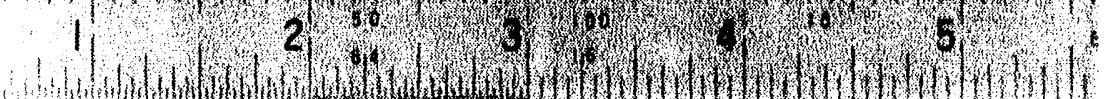

Fig. 9. Typical 40 vol.\% $10_{B}$ compact (balance copper)
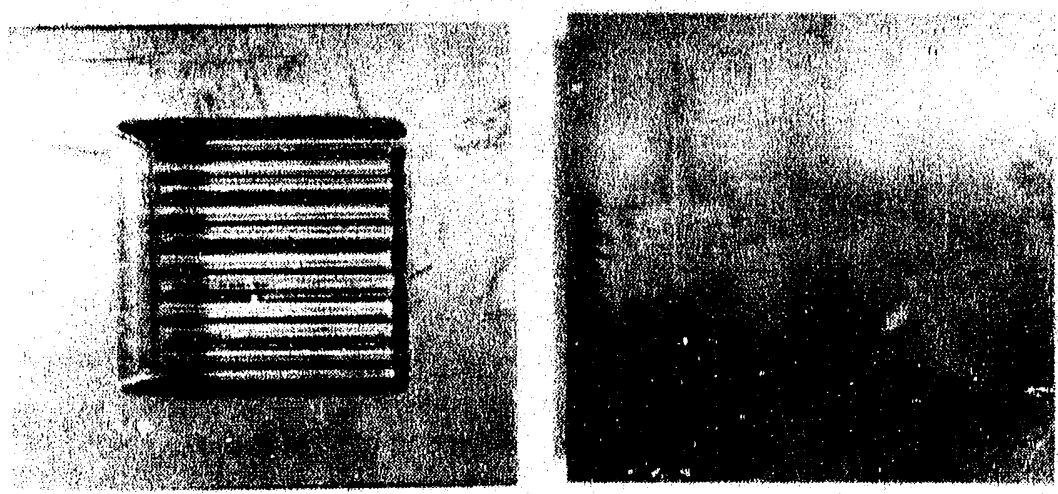

1.t.

Fig. 10. Copper frame and cover plate for cladding of $10^{B}-\mathrm{Cu}$ compact 


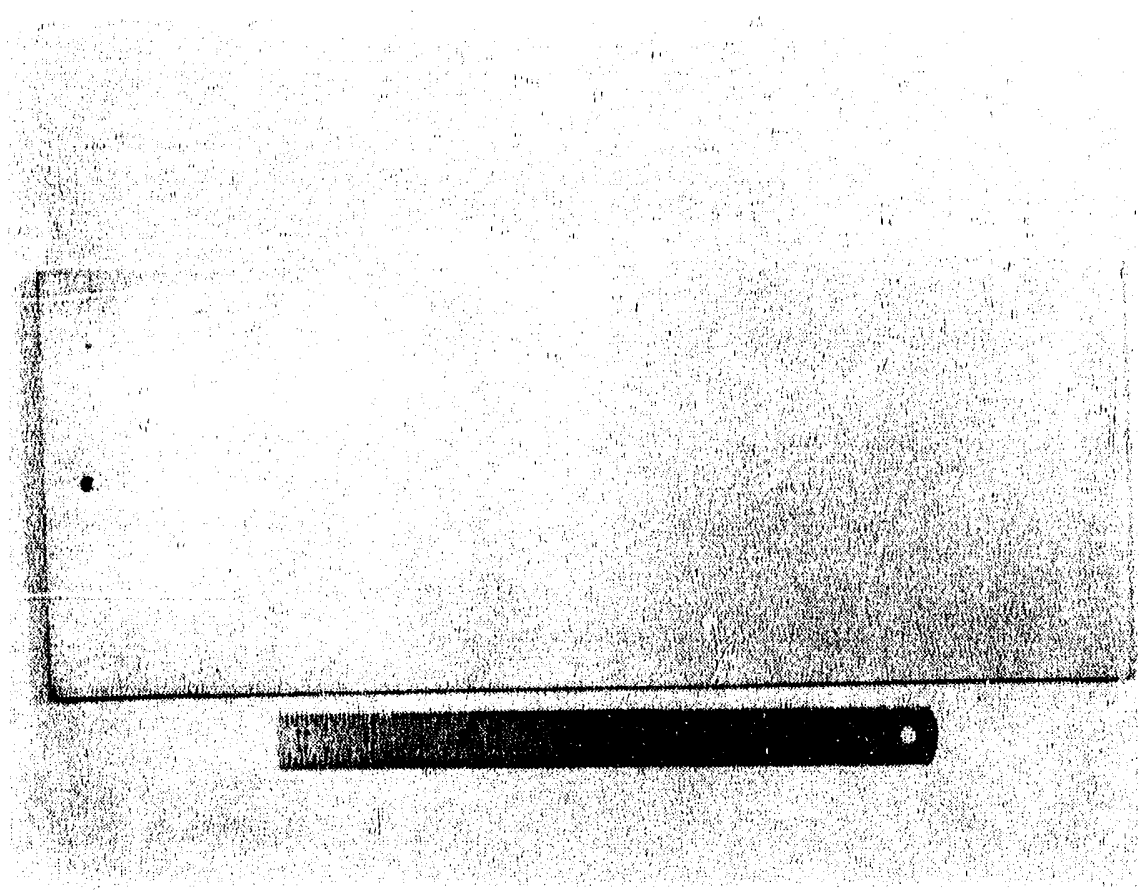

Fig. 11. Typical hot-rolled $10_{B}-\mathrm{Cu}$ plate

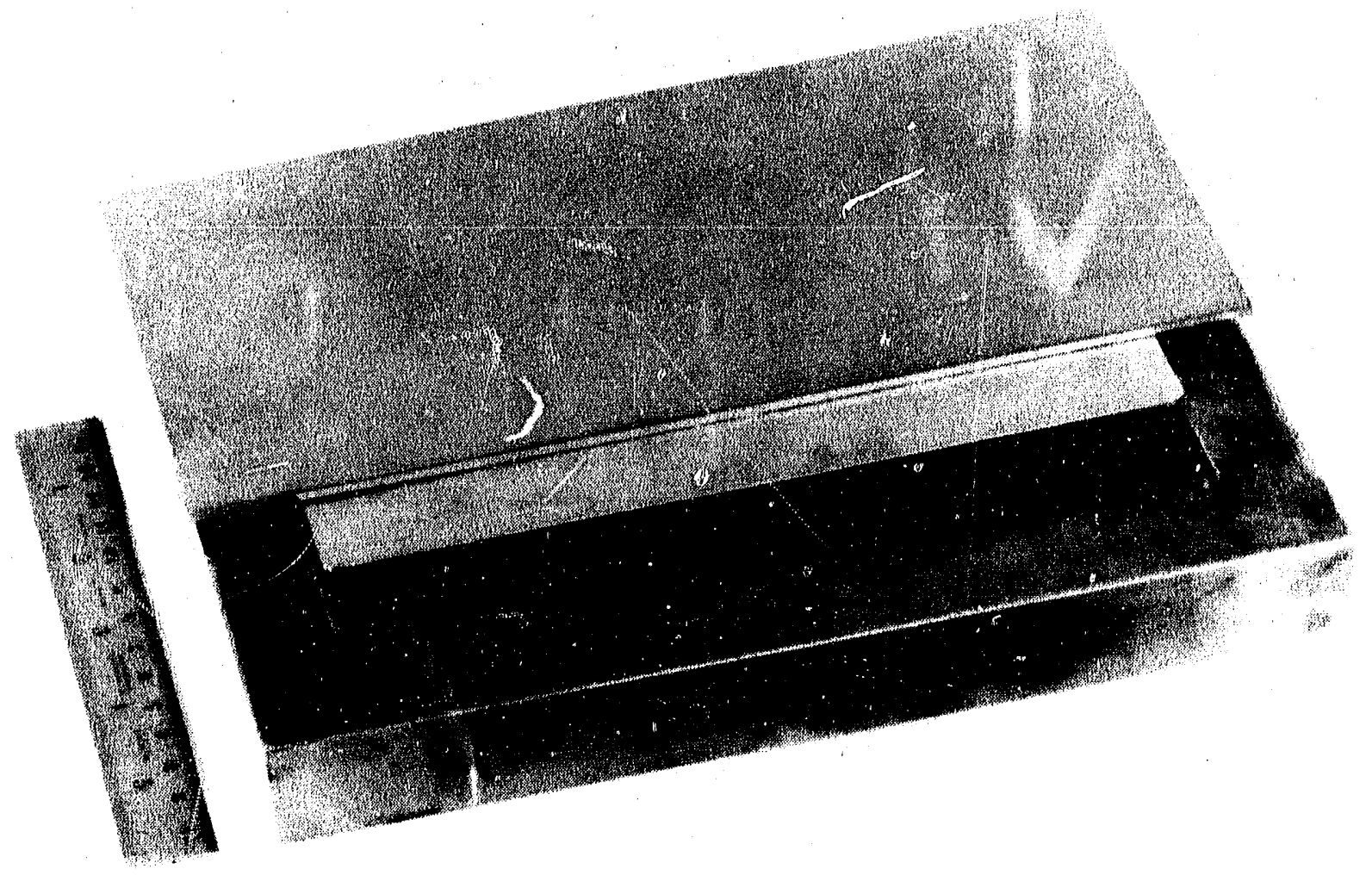

Fig. 12. ${ }^{10} \mathrm{~B}-\mathrm{Cu}$ triple-compact assembly 


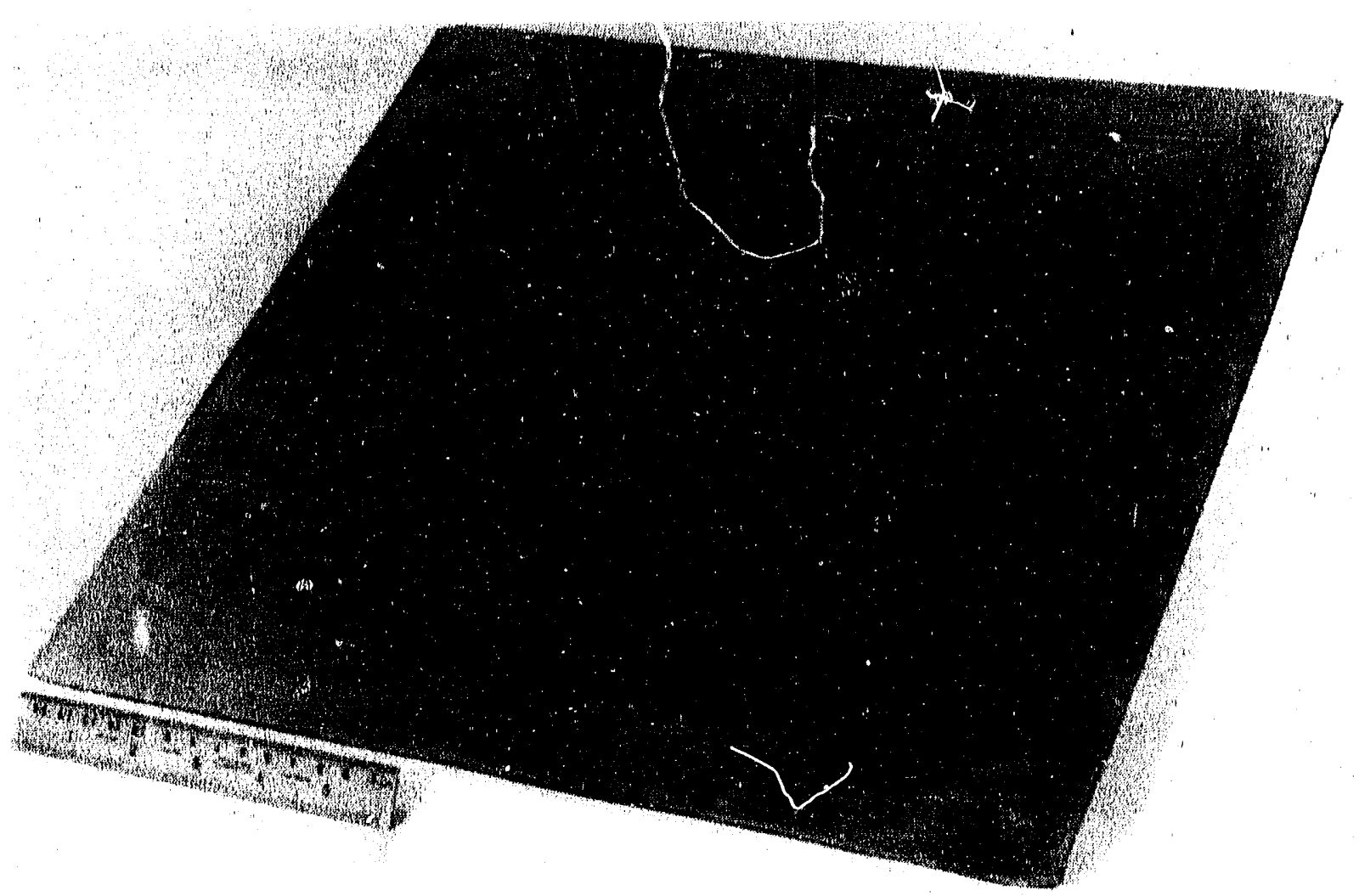

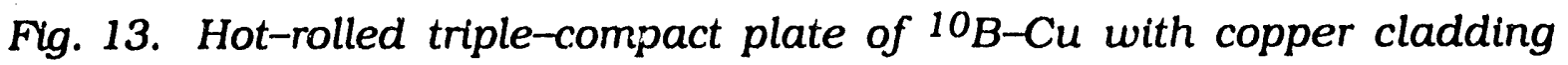

cross-rolled. This proved to be the best method, yielding a plate with 42 vol.\% boron and only 18 vol.\% void. This method was used on all the remaining assemblies. The boron loadings of the next four plates produced by hot-rolling and cross-rolling ranged from $41-44$ vol.\% and voids ranged from 15-20 vol.\%. Overall, these values meet the design requirements and are acceptable for the IPNS.

A metallographic sample was taken from the first production Assembly (No. 4) to determine various properties. Figure 14 shows a cross section after hot-rolling. There is a very good distribution of boron particles, which appear as gray areas. A large amount of porosity and/or pullout, represented by black areas, is also apparent. Figure 15, a higher magnification of the same sample, shows no visible evidence of reaction between the copper matrix and the boron. 
Table 5. Effect of fabrication technique on percent porosity in meat

\begin{tabular}{|c|c|c|c|c|}
\hline $\begin{array}{c}10 \mathrm{~B}-\mathrm{Cu} \\
\text { Assembly } \\
\text { Identification }\end{array}$ & $\frac{\text { Volume Pers }}{\text { Copper }}$ & $\frac{\text { nt in Finishe }}{\text { Boron }}$ & $\frac{\text { Assembly }}{\text { Void }}$ & $\begin{array}{c}\text { Fabrication } \\
\text { History }\end{array}$ \\
\hline 1 & 44 & 35 & 21 & $\begin{array}{l}\text { Hot-Rolled } 900^{\circ} \mathrm{C} \\
\text { Not Cross Rolled }\end{array}$ \\
\hline 2 & 36 & 38 & 26 & $\begin{array}{l}\text { Hot-Rolled } 900^{\circ} \mathrm{C} \\
\text { Cold-Rolled, } \\
\text { Not Cross-Rolled }\end{array}$ \\
\hline 3 & & $\begin{array}{c}\text { Not } \\
\text { Measured }\end{array}$ & & $\begin{array}{l}\text { Hot-Rolled } 900^{\circ} \mathrm{C} \\
\text { Not Cross-Rolled }\end{array}$ \\
\hline 4 & 40 & 42 & 18 & $\begin{array}{l}\text { Hot-Rolled } 900^{\circ} \mathrm{C} \\
\text { Cross-Rolled }\end{array}$ \\
\hline 5 & 40 & 43 & 17 & $\begin{array}{l}\text { Hot-Rolled } 900^{\circ} \mathrm{C} \\
\text { Hot-Rolled } 650^{\circ} \mathrm{C} \\
\text { Cross-Rolled }\end{array}$ \\
\hline $\begin{array}{c}\quad 6 \\
\text { (Before roll- } \\
\text { forming) }\end{array}$ & 41 & 44 & 15 & $\begin{array}{l}\text { Hot-Rolled } 900^{\circ} \mathrm{C} \\
\text { Hot-Rolled } 650^{\circ} \mathrm{C} \\
\text { Cross-Rolled }\end{array}$ \\
\hline $\begin{array}{l}6 \\
\text { (After roll- } \\
\text { forming) }\end{array}$ & 41 & 43 & 16 & $\begin{array}{l}\text { Hot-Rolled } 900^{\circ} \mathrm{C} \\
\text { Hot-Rolled } 650^{\circ} \mathrm{C} \\
\text { Cross-Rolled } \\
\text { Roll-Formed }\end{array}$ \\
\hline 7 & 39 & 41 & 20 & $\begin{array}{l}\text { Hot-Rolled } 900^{\circ} \mathrm{C} \\
\text { Hot-Rolled } 650^{\circ} \mathrm{C} \\
\text { Cross-Rolled }\end{array}$ \\
\hline 8 & 40 & 42 & 18 & $\begin{array}{l}\text { Hot-Rolled } 900^{\circ} \mathrm{C} \\
\text { Hot-Rolled } 650^{\circ} \mathrm{C} \\
\text { Cross-Rolled }\end{array}$ \\
\hline
\end{tabular}

aBased on water-immersion density measurements. 


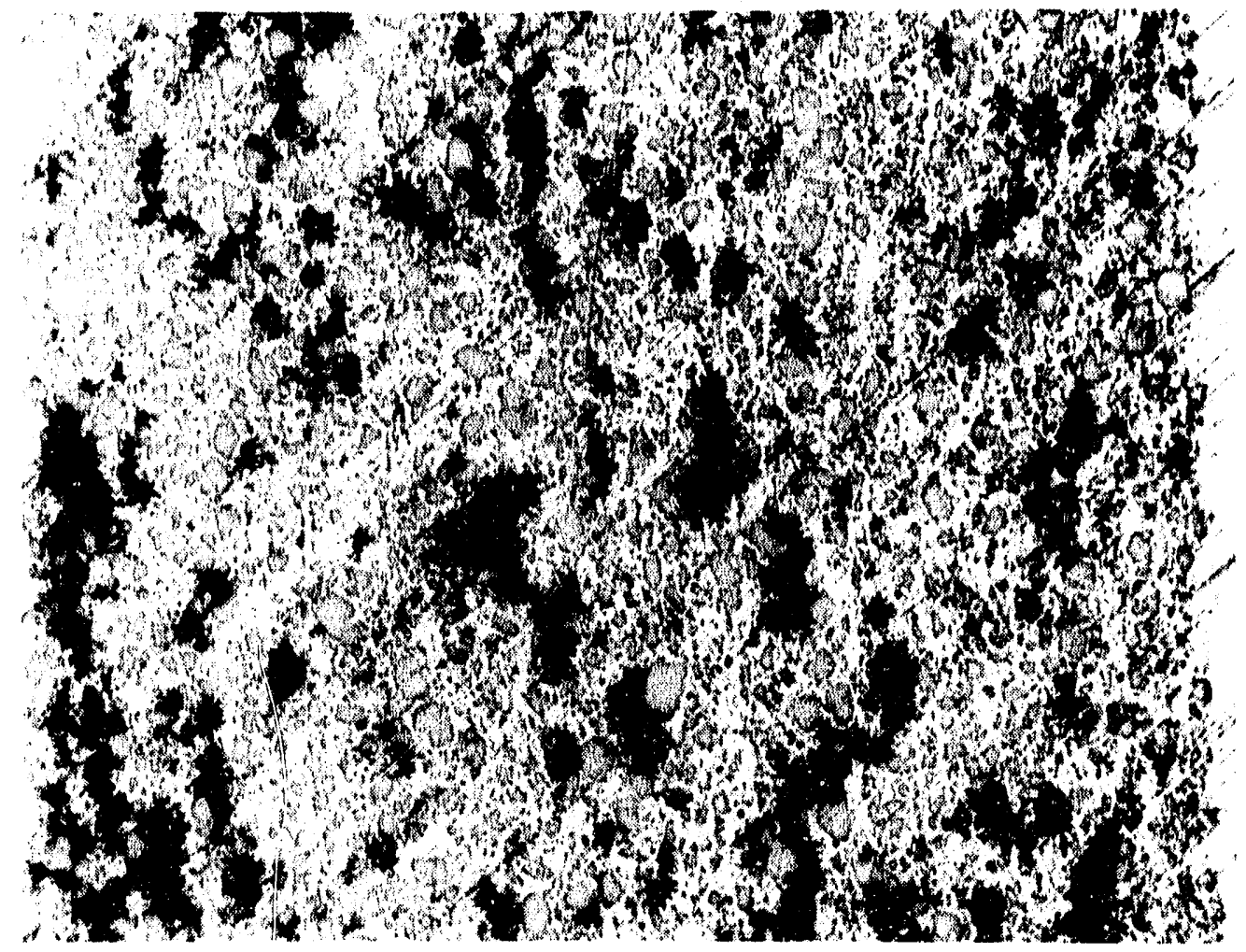

Fig. 14. Cross section of Assembly 4 after hot rolling (75X)

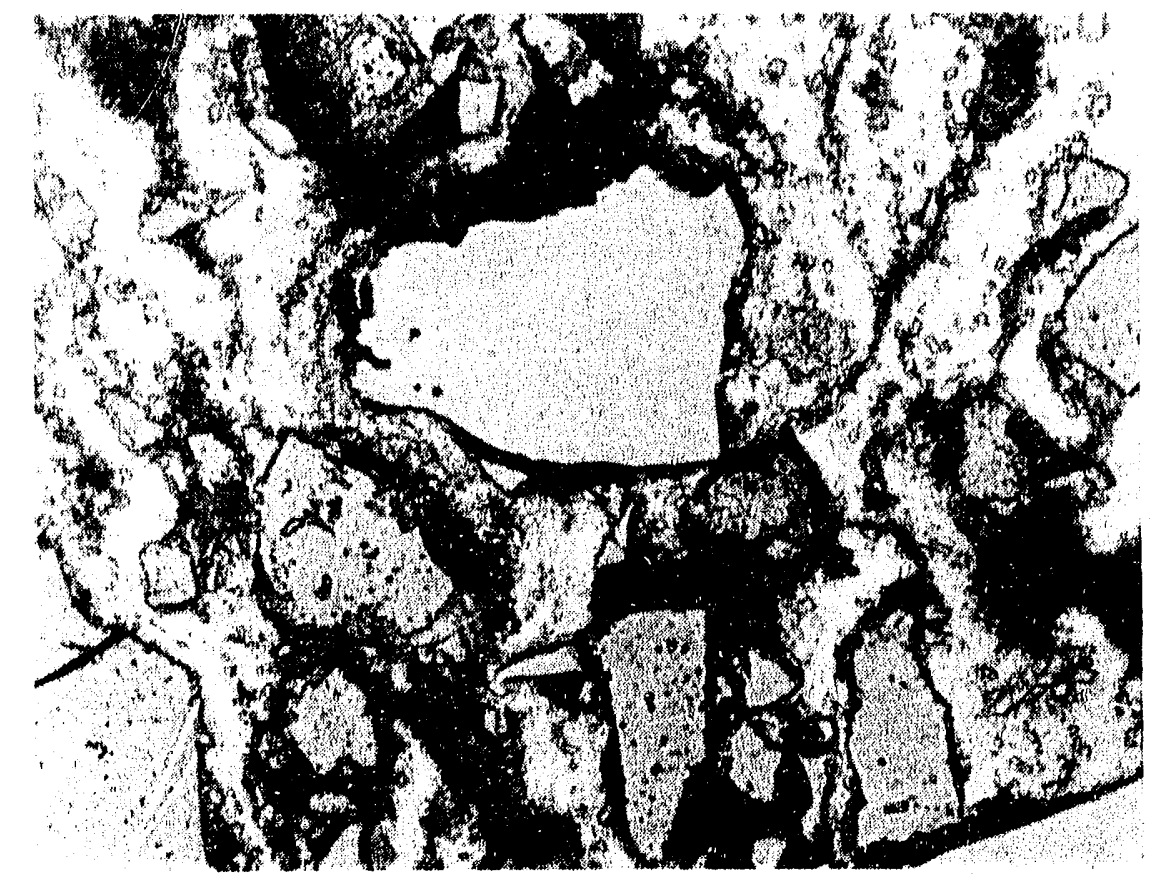

Fig. 15. Cross section of Assembly 4 after hot rolling (500X) 
The same metallographic sample was also used to determine clad thickness, which was measured as $0.015 \pm 0.001$ in. $(0.4 \pm 0.02 \mathrm{~mm})$. The corresponding meat thickness was $0.105 \pm 0.003 \mathrm{in} .(2.6 \pm 0.07 \mathrm{~mm})$. These values are quite acceptable and are typical of this type of composite structure.

The meat thickness of Assembly 4 was also confirmed indirectly by reading an X-ray of the plate with a densitometer. A copper step-wedge of known thicknesses was also included on the same film as a standard. An average random equivalent copper density was then calculated for the plate. The meat was determined to be $0.101 \mathrm{in}$. thick. This compares favorably with the metallographically measured value of $0.105 \mathrm{in}$. The difference could be due to porosity or to the boron X-ray absorption, which is assumed to be zero but is not $100 \%$ transparent. This analysis was repeated for Assembly 6, with similar results. It is impossible to absolutely confirm the distribution of the boron by this technique, but from the metallography and from previous work with dispersion fuel plates, it can be reasonably assumed that the boron is evenly distributed in the copper matrix.

After establishing the (a) meat thickness from the metallography or $\mathrm{X}$-ray analysis, (b) vol.\% boron, (c) wt.\% boron, and (d) wt.\% ${ }^{10} \mathrm{~B}$ from the chemical analysis, the ${ }^{10} \mathrm{~B}$ loading can be determined by the procedure described below.

Assuming 0.105 in. for the meat thickness (determined by metallography) and a uniform distribution of $100 \%{ }^{10} \mathrm{~B}$, there would be $3.774 \times 10^{22} 10 \mathrm{~B}$ atoms $/ \mathrm{cm}^{2}$ of surface area.

For Assembly 4:

(vol.\% boron)(wt. fraction boron)(wt. fraction $10 \mathrm{~B})=$ vol. $\%{ }^{10} \mathrm{~B}$ $(42.0)(0.897)(0.9029)=34.01 \mathrm{vol} . \% 10 \mathrm{~B}$,

$3.774 \times 10^{22}$ (vol. fraction ${ }^{10} \mathrm{~B}$ ) $=$ atoms $/ \mathrm{cm}^{2}$ when meat thickness is 0.105 in.

$\left(3.774 \times 10^{22}\right)(0.3401)=1.284 \times 10^{22} 10 \mathrm{~B}$ atoms $/ \mathrm{cm}^{2}$.

A realistic estimate of the range of the last value is probably $\pm 5 \%$, which leaves the value above the minimal requirement of $1.0 \times 10^{2210} \mathrm{~B}$ atoms $/ \mathrm{cm}^{2}$. 
For a meat thickness of $0.101 \mathrm{in.} \mathrm{(determined} \mathrm{by} \mathrm{X-ray} \mathrm{analysis),} \mathrm{the}$ loading would be $1.235 \times 10^{2210} \mathrm{~B}$ atoms $/ \mathrm{cm}^{2}$.

A simpler method to determine the areal boron loading is to measure the area of the as-hot-rolled sheet using the location X-ray and the equation

Wt. of $\mathrm{B}$ in compact (g)/Area (in. $\left.{ }^{2}\right) \times 7.561 \times 10^{21}=10^{\mathrm{B}}$ atoms $/ \mathrm{cm}^{2}$. For Assembly 4, 10B-Cu Area $=24.662$ in. ${ }^{2}\left(=159.11 \mathrm{~cm}^{2}\right)$; $10 \mathrm{~B}$ atoms $/ \mathrm{cm}^{2}=1.253 \times 10^{22}$.

This method was used to calculate the ${ }^{10} \mathrm{~B}$ loadings of all plates after Assembly 4. The results for all production plates are summarized in Table 6 .

As a fourth and final check to confirm the boron loadings, samples from Assemblies 4-6 were analyzed by the ANL Chemical Technology Division. Table 7 substantiates, by chemical analysis of the boron loading, that the four methods were quite similar. The third method, which is the most costeffective and is sufficiently accurate, was used to determine the ${ }^{10} \mathrm{~B}$ loading of the remaining plates. Assemblies 7-13 were not analyzed chemically.

One material-property requirement was that the sample retain its integrity after $7 \mathrm{~h}$ in air at $900^{\circ} \mathrm{C}$. Time-at-temperature tests of the composite material proved successful and demonstrated that high temperatures can be sustained. A $2 \times 2$ in. piece of 0.074 -in.-thick ${ }^{10} \mathrm{~B}-\mathrm{Cu}$ composite $(0.050$ in. meat, $2 \times 0.012$ in. clad) was tested in air for 7 at $895^{\circ} \mathrm{C} \pm 5^{\circ}$. A similar piece of solid oxygen-free high-conductivity (OFHC) copper was included as a control. The results of the test are given in Table 8.

The samples did not fail, but accumulated a heavy coat of oxide (Fig. 16). However, the copper regained its luster after cleaning, as shown in Fig. 17. The uneven surface evident in Figs. 16 and 17 formed during the original hot-rolling of the sample, which was conducted in air at $900^{\circ} \mathrm{C}$.

Metallography showed that a slight reaction had taken place but this would cause little or no problem (Fig. 18). Collectively, the results were very acceptable.

Overall, the design goals were met, except in the cases of two pieces of decoupler located in the bore tube, where the reduced level of $10 \mathrm{~B}$ atoms 
Table 6. Measurement of $10_{B}$ Loadings

\begin{tabular}{|c|c|c|c|c|}
\hline \multirow{2}{*}{$\begin{array}{l}10_{\mathrm{B}-\mathrm{Cu}} \\
\text { Assembly } \\
\text { Number }\end{array}$} & \multirow{2}{*}{$\begin{array}{c}\text { X-ray } \\
\text { Area } \\
\text { (in. }^{2} \text { ) }\end{array}$} & \multirow{2}{*}{$\begin{array}{c}\text { Wt. of } \\
\text { Boron } \\
(\mathrm{g})\end{array}$} & \multicolumn{2}{|c|}{$10_{\mathrm{B}}$ Loading $\left(10^{22}\right.$ atoms $\left./ \mathrm{cm}^{2}\right)$} \\
\hline & & & Actual $^{\mathrm{a}}$ & Target \\
\hline $4^{b}$ & -- & 40.814 & 1.284 & 1.00 \\
\hline 4 & 24.66 & 40.814 & 1.253 & 1.00 \\
\hline $4^{c}$ & -- & 40.814 & 1.235 & 1.00 \\
\hline 5 & 77.571 & 55.019 & 0.536 & 0.50 \\
\hline 6 & 77.369 & 54.680 & 0.534 & 0.50 \\
\hline $6^{c}$ & -- & 54.680 & 0.514 & 0.50 \\
\hline 7 & 48.834 & 72.209 & 1.118 & 1.00 \\
\hline 8 & 43.474 & 72.409 & 1.259 & 1.00 \\
\hline 9 & 88.345 & 146.271 & 1.252 & 1.00 \\
\hline 10 & 87.685 & 145.607 & 1.256 & 1.00 \\
\hline 12 & 172.415 & 218.089 & 0.956 & 1.00 \\
\hline 13 & 168.166 & 218.993 & 0.985 & 1.00 \\
\hline
\end{tabular}

aAll values, except the first, third, and sixth, were calculated using the equation

Weight $(\mathrm{g}) /$ Area (in. $\left.{ }^{2}\right)\left(7.561 \times 10^{21}\right)=$ Loading $\left({ }^{10} \mathrm{~B}\right.$ atoms $\left./ \mathrm{cm}^{2}\right)$.

bCalculated from metallographic-thickness measurements.

CCalculated from X-ray densitometer readings. 
Table 7. Comparison of booster target $10_{B}$ atom area densities determined by various methods

\begin{tabular}{lccccc}
\hline & & \multicolumn{4}{c}{ Alom Area Density $\left(10^{22} 10_{\mathrm{B} \text { atoms } / \mathrm{cm}^{2} \mathrm{~A}}\right.$} \\
\cline { 3 - 6 } & $\begin{array}{c}\text { 10 } \\
\text { Assembly } \\
\text { Identification }\end{array}$ & $\begin{array}{c}\text { Expected by } \\
\text { Letallographic } \\
\text { Methods }\end{array}$ & $\begin{array}{c}\text { Expected by } \\
\text { Densitometer } \\
\text { Readings from } \\
\text { X-Rays }\end{array}$ & $\begin{array}{c}\text { Expected } \\
\text { by Area } \\
\text { Measurement }\end{array}$ & $\begin{array}{c}\text { Measured } \\
\text { by Chemical } \\
\text { Analysis }\end{array}$ \\
\hline Spring Housing & 4 & 1.284 & 1.235 & 1.253 & 1.216 \\
Vessel Wall & 5 & Not Measured & Not Measured & 0.536 & 0.5185 \\
Vessel Wall & 6 & Not Measured & 0.514 & 0.534 & 0.5220 \\
\hline
\end{tabular}

Table 8. Results of time-at-temperature tests $\left(7 \mathrm{~h}\right.$ at $\left.900^{\circ} \mathrm{C}\right)$

\begin{tabular}{|c|c|c|c|c|}
\hline \multirow{2}{*}{$\begin{array}{l}\text { Sample } \\
\text { Description }\end{array}$} & \multicolumn{3}{|c|}{ Dimensions (in.) } & \multirow[b]{2}{*}{ Weight (g) } \\
\hline & Widtha & Length & Thickness & \\
\hline
\end{tabular}

$\mathrm{Cu}$ Sheet

$\begin{array}{lrrrr}\text { As fabricated } & 2.037 & 2.041 & 0.072 & 40.154 \\ \text { After testing } & 2.036 & 2.038 & 0.053 & 30.147 \\ \text { Change } & -0.001 & -0.003 & -0.019 & -10.007\end{array}$

${ }^{10} \mathrm{~B}-\mathrm{Cu}$ Sheet

$\begin{array}{lrrrr}\text { As fabricated } & 2.016 & 2.034 & 0.074 & 28.341 \\ \text { After testing } & 2.028 & 2.043 & 0.060 & 20.257 \\ \text { Change } & +0.012 & +0.009 & -0.014 & -.8 .084\end{array}$

aLength is defined arbitrarily as the dimension in the rolling direction; width is $90^{\circ}$ to the rolling direction. 

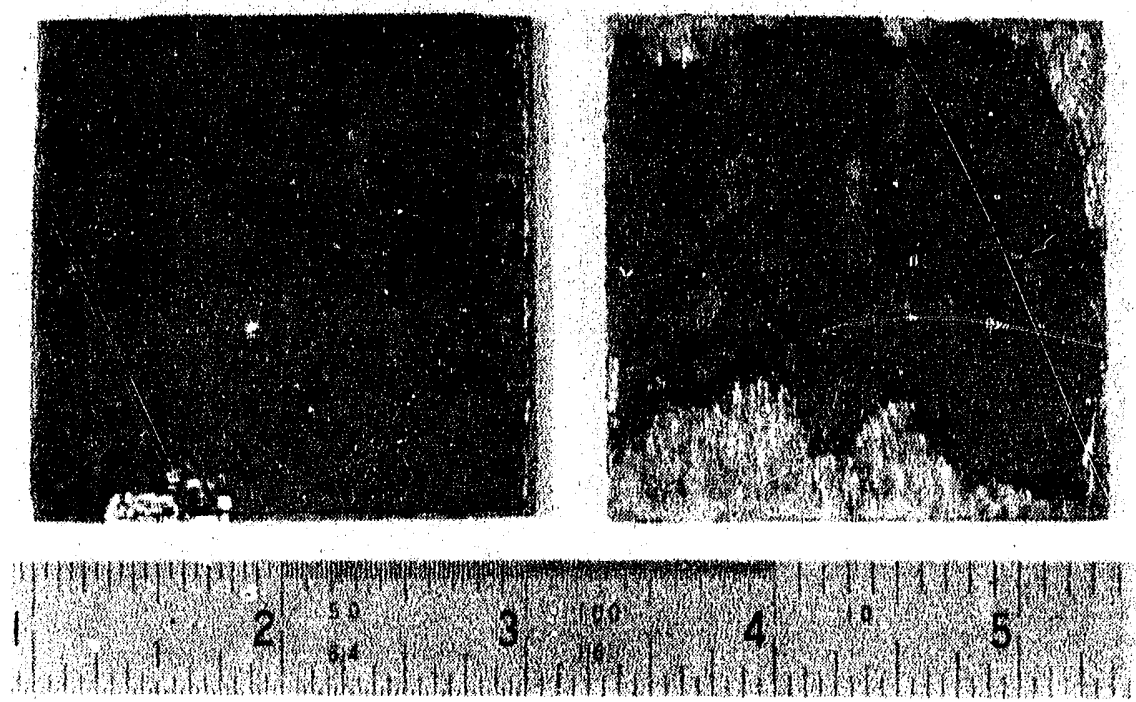

Fig. 16. Sample of Assembly 1 after heat treatment in air for $7 \mathrm{~h}$ at $895^{\circ} \mathrm{C}$

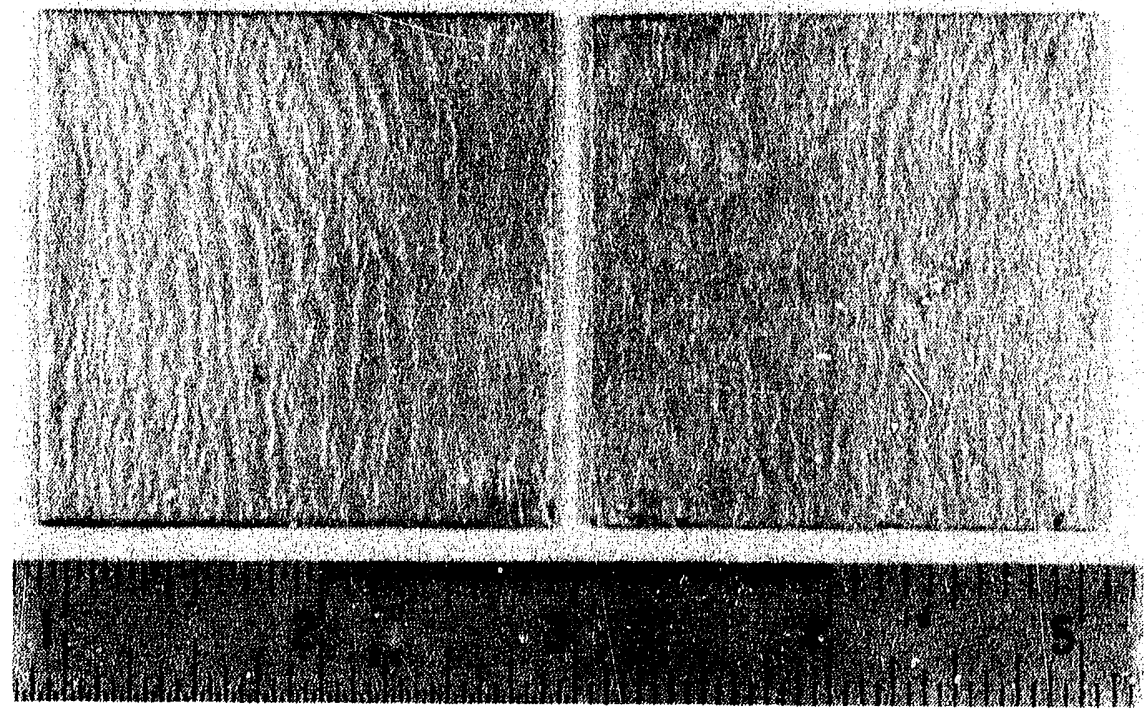

Fig. 17. Sample of Assembly 1 after heat treatment in air and cleaning 


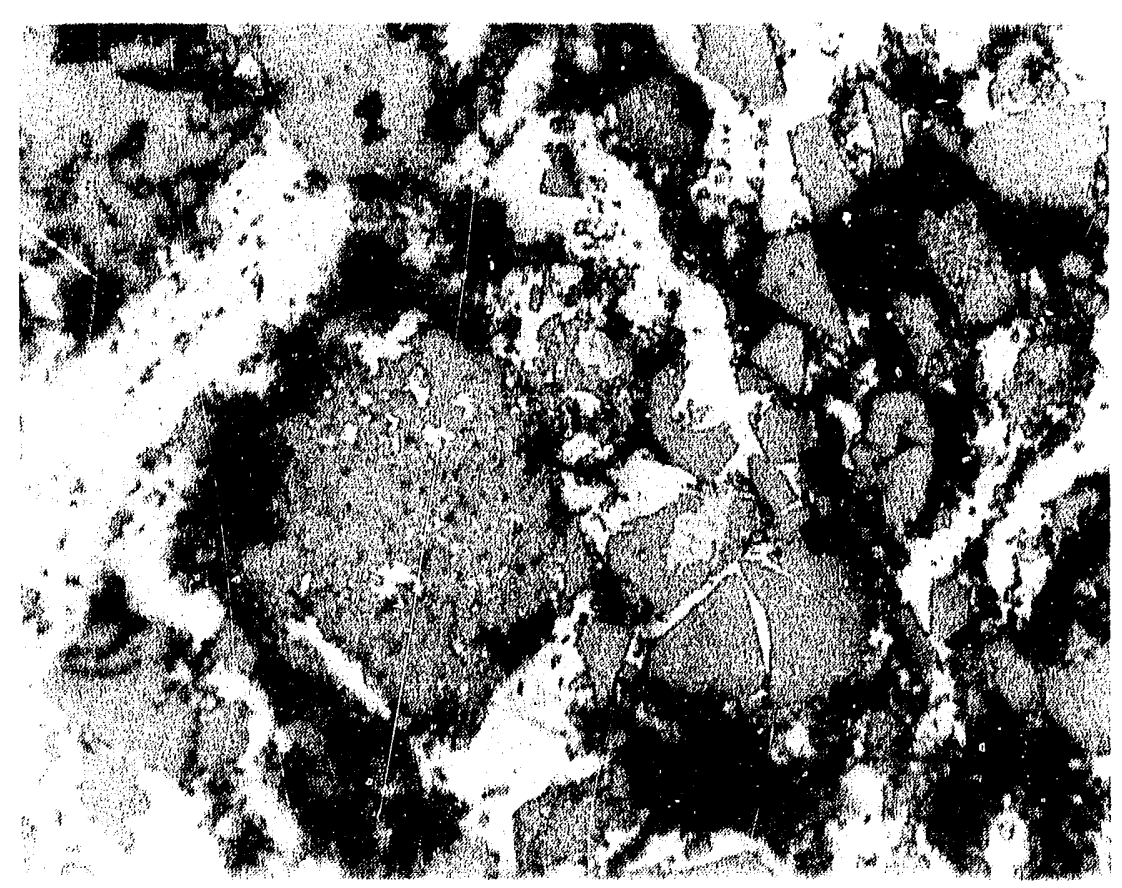

Fig. 18. Metallographic sample of Assembly 1 after $7 \mathrm{~h}$ at $900^{\circ} \mathrm{C}$ and protection from severe exposure to air (500X)

was considered insignificant $(4.4 \%$ and $1.5 \%)$. With the stock made, the next fabrication steps were forming and machining.

\section{Machining, Roll-Forming, and Assembly of Stock 10B-Cu Plates into Finished Hardware}

The first shape to be machined was a simple flat disc. ${ }^{10} \mathrm{~B}-\mathrm{Cu}$ No. 4 was rough-sized with an abrasive cutoff wheel, without coolant. The cut edge was very good and there was little fallout. The piece was sandwiched between aluminum plates and then turned in a lathe to the proper diameter. The boron was very abrasive and although the tooling had to be resharpened often, the piece was successfully machined to size.

The finished internal spring support decoupler insert is shown in Fig. 19. During the machining, pushing of the material into the backup block caused a ridge to form on the piece; to correct this problem, future pieces were ground or cut to size with a diamond cutoff wheel. 
The second shape to be machined was a 0.066-in.-thick semicircle with rounded corners. The flat plate stock was first roll-formed to the required radius. This was done in multiple passes, with softening anneals between each pass. When the plate was at the proper radius, it was attached to a mandrel and cut to size with a diamond-impregnated cutting wheel mounted on a horizontal milling machine. This process, illustrated in Fig. 20 , produced stepped shapes (as shown in the figure) and straight edges. The only drawback was the slowness of the process. Only light cuts $(0.005-$ 0.015 in.) could be made, but the material showed very little tendency of the boron to fall out of the copper. The rounded corners were shaped by carefully grinding the excess material away with a belt sander up to a scribed guide line. The finished piece is shown in Fig. 21. A nearly identical shape was machined from Assembly 5 for the matching shield.

The next shape to be produced was very similar to the previous one; at 0.135 in., however, it was more than twice as thick. The four-piece assembly also had overlapping steps. An exploded view of the assembly, with details of the lap joint is presented in Fig. 22. The final production piece is shown in Fig. 23, along with the supporting structure. No major problems were encountered during production, which included drilling the material with tungsten-carbide-coated drill bits. However, meat degradation (a loss of homogeneity) could be seen on the inspection X-rays when the number of compacts was increased to two per assembly. This was the first double compact assembly to be rolled.

The loss of homogeneity in multicompact plates could be due to rolling or roll-forming. When the final piece (which was even larger and required a triple-compact assembly) was produced, two changes were made in the process. A double can was used (as detailed in the flat-plate production section) to reduce degradation from rolling, However, roll forming also degraded the plate homogeneity. To preclude cracking on the tension side of the plate during roll-forming, a heavy copper backup sheet was softsoldered to the outside of the plate. This sheet took most of the tensile force during roll-forming and kept the shield plate in compression. By keeping the production plate in compression, a more homogeneous curved plate was produced. The soldering and roll-forming is shown in Fig. 24. The finished production assembly, attached with screws to a stainless steel support tube, is shown in Fig. 25. 


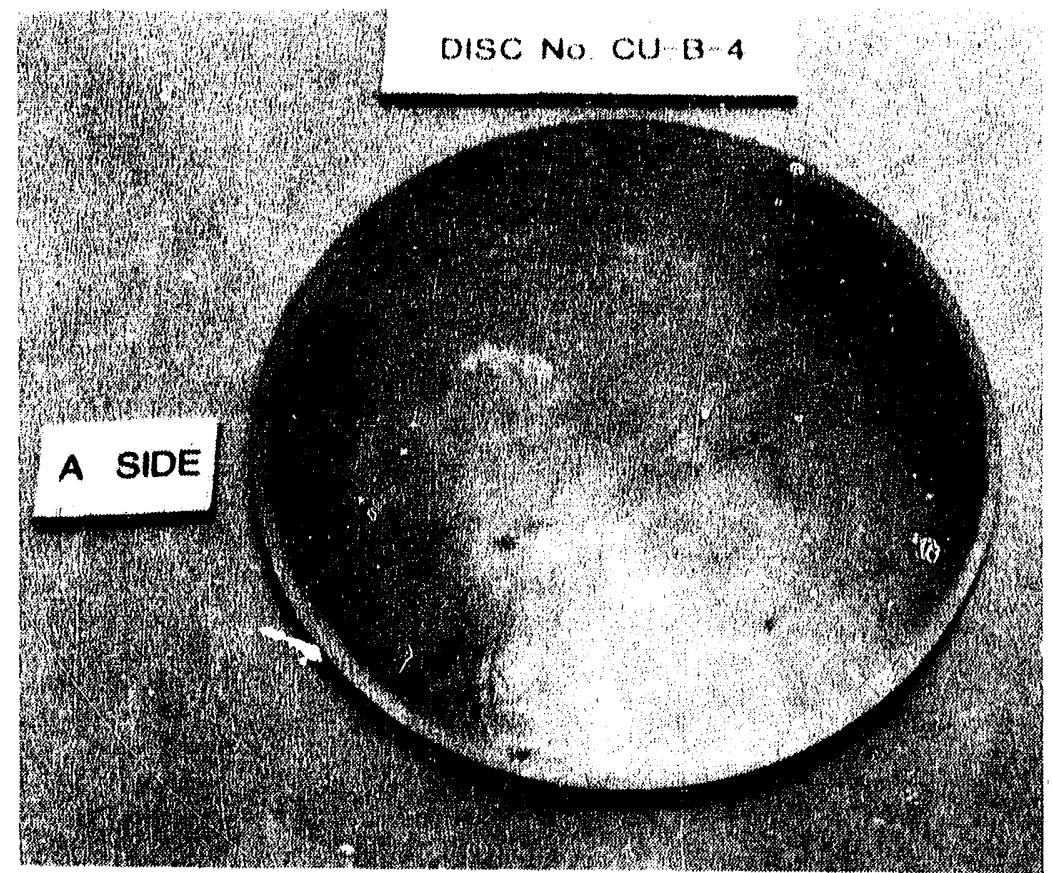

Fig. 19. Finished internal spring support decoupler insert, Side A

IIIII() YI) MUIRE(BNITEI) (T'TTISC; HHEEL

M.I'HINEL) H.LLF L.AP JOINT

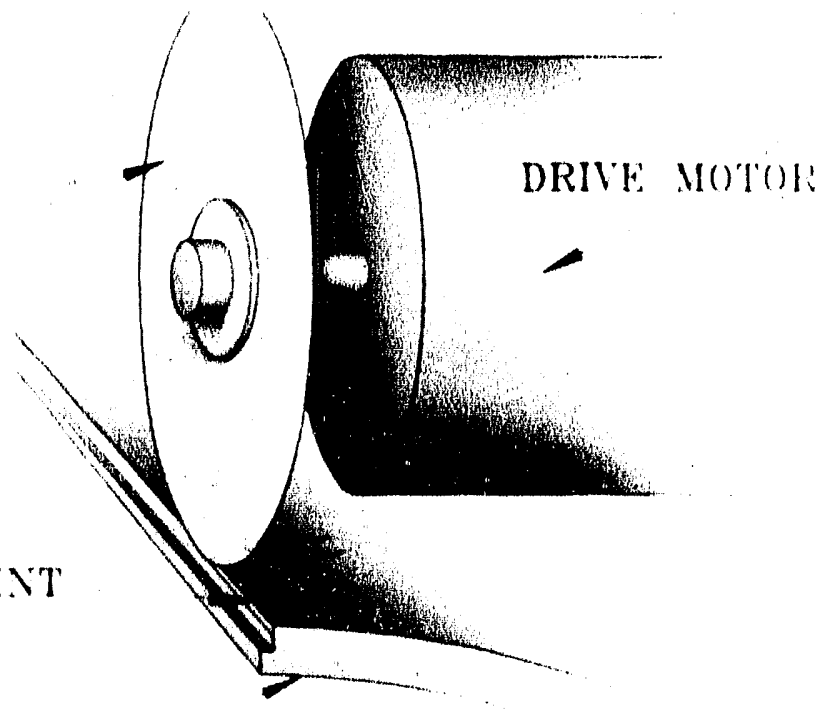

HMF TLBE SE(THON

Fig. 20. Machining of the ${ }^{10} \mathrm{~B}-\mathrm{Cu}$ composite 


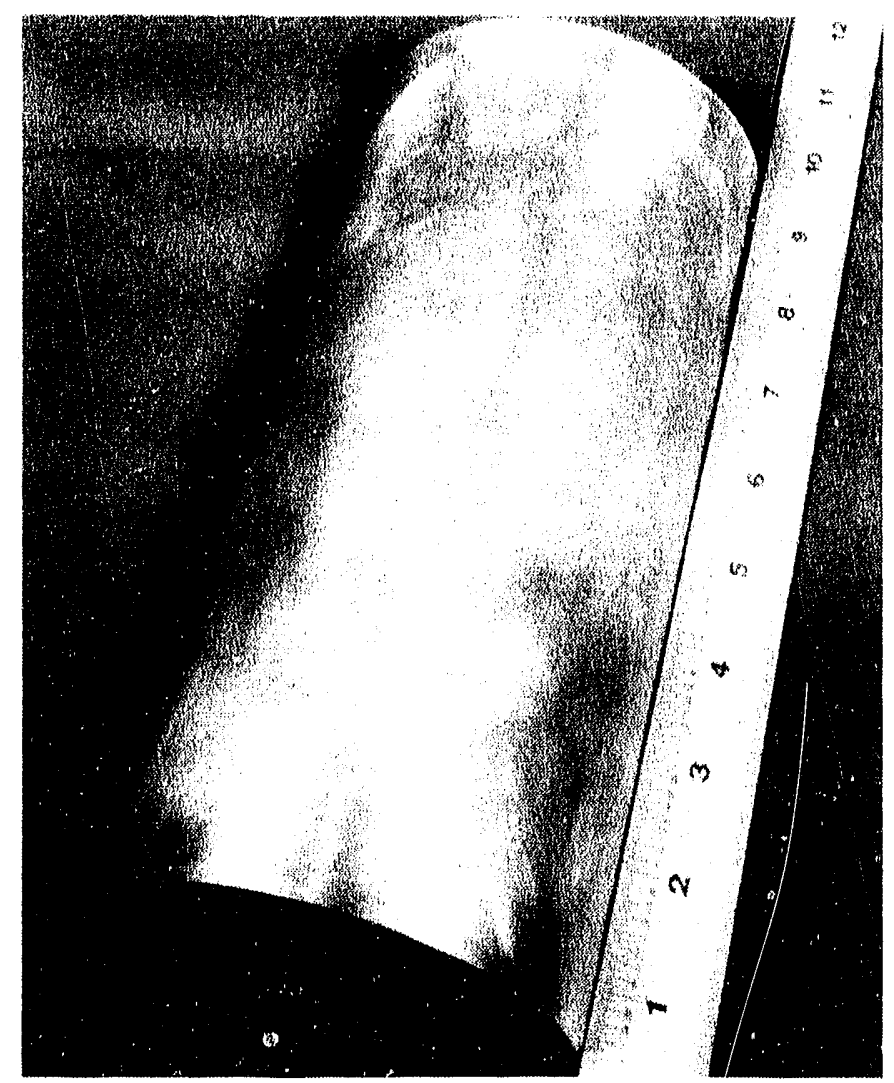

Fig. 21. Finished IPNS booster target housing decoupler insert 


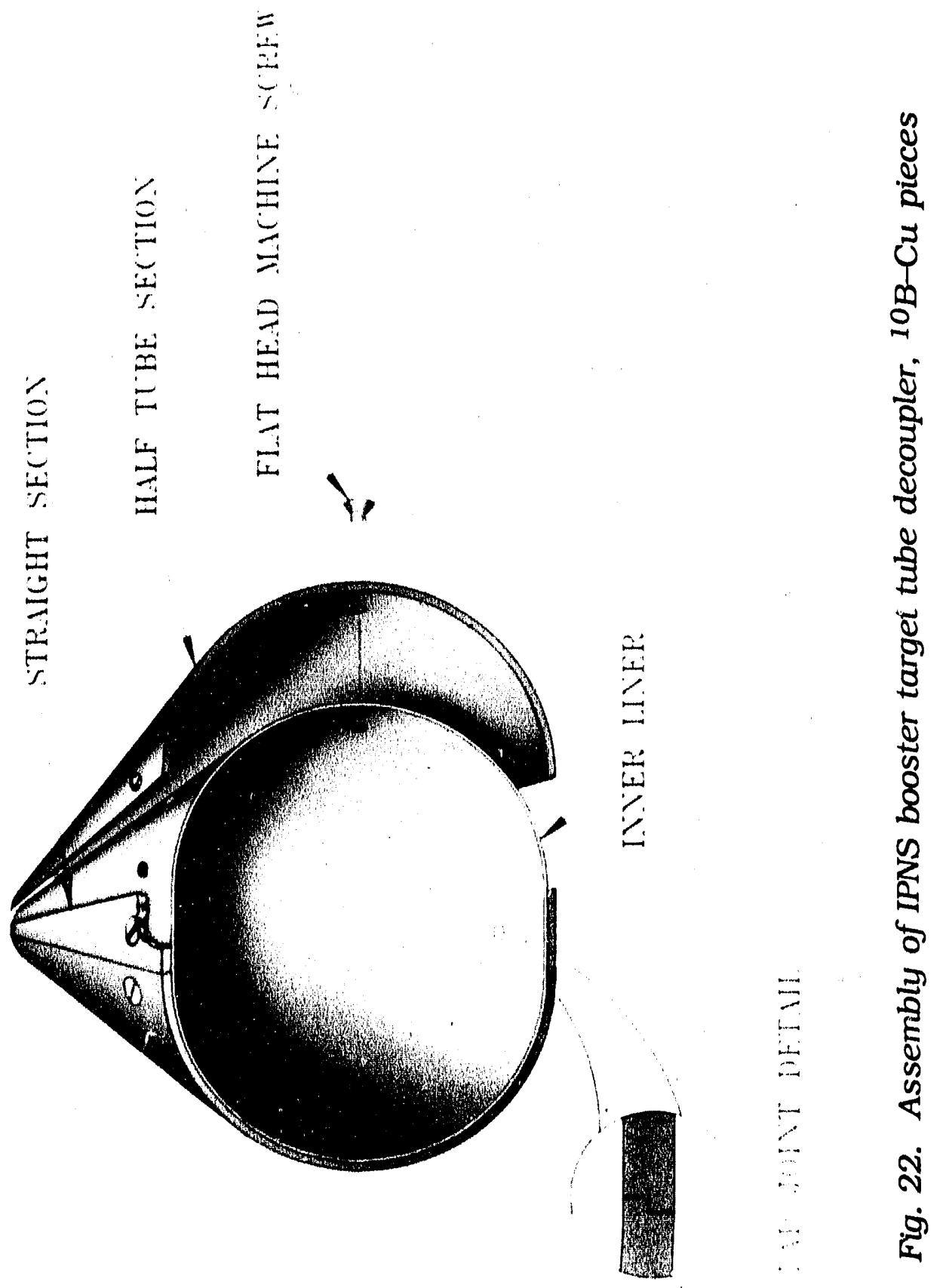




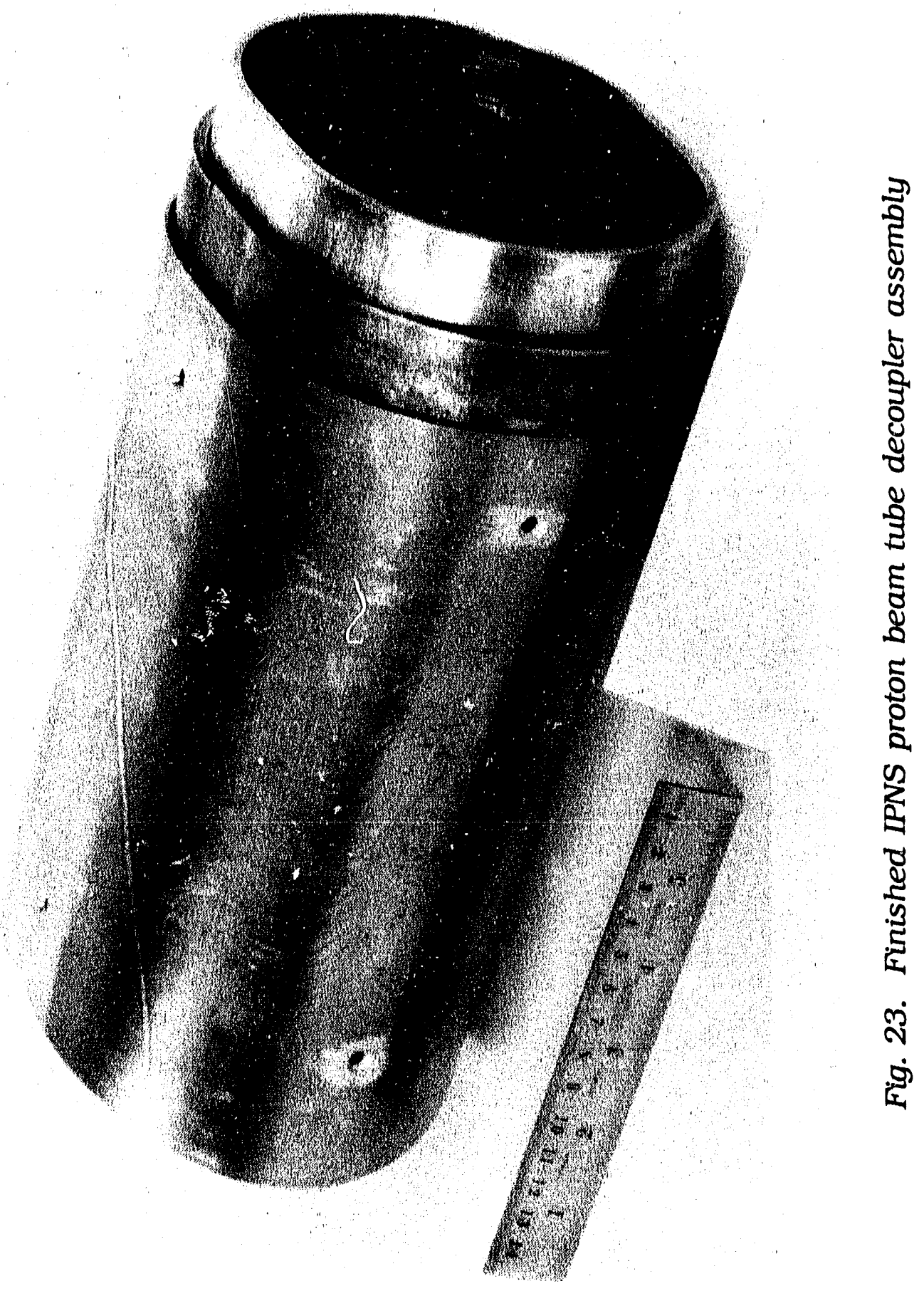




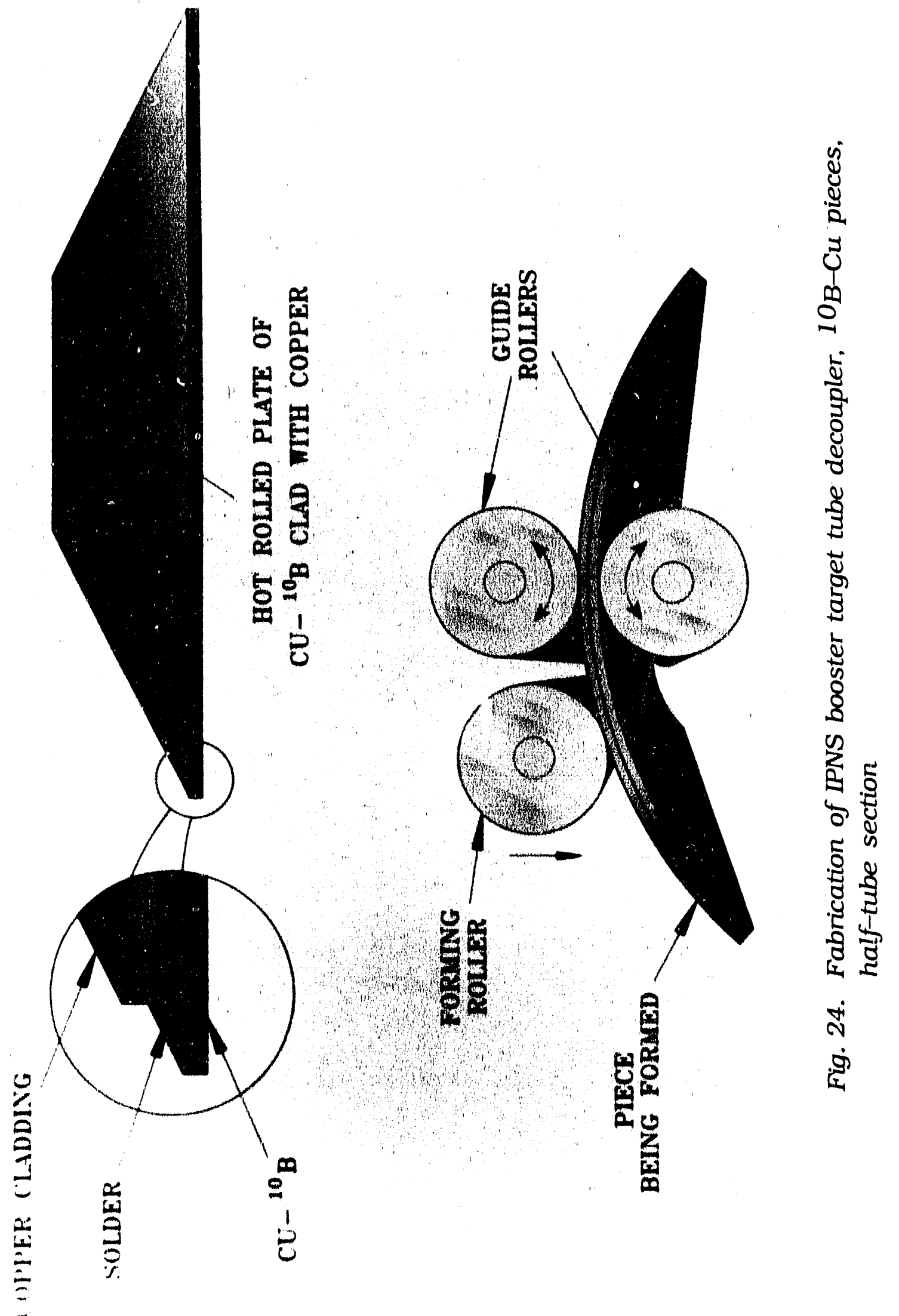




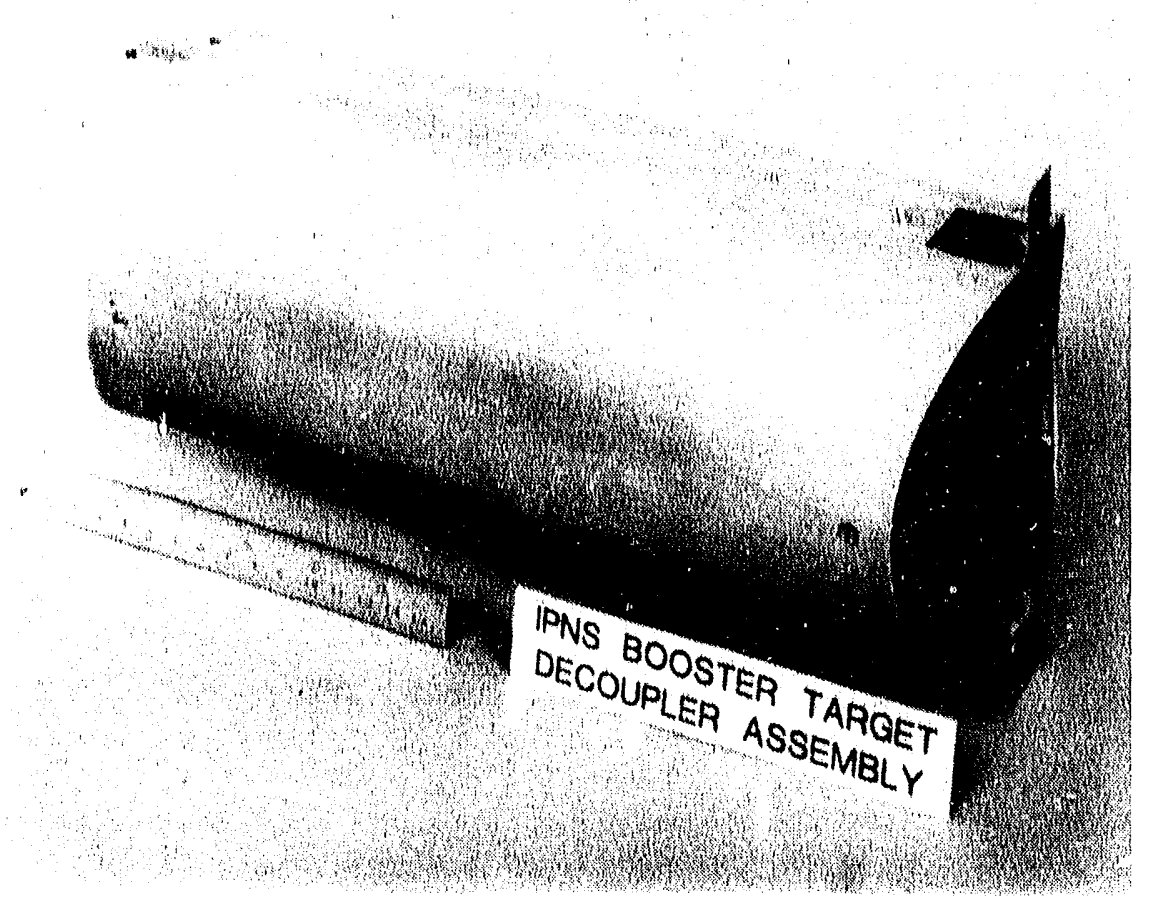

Fig. 25. IPNS booster target decoupler assembly

\section{Conclusions}

All finished hardware was shipped to IPNS and accepted for insertion into the neutron source. The upgraded IPNS went on line October 11, 1988 and produced the predicted boost in neutron production of almost three times the original-design neutron density. A statutory patent on the invention and innovative processing of the ${ }^{10} \mathrm{~B}-\mathrm{Cu}$ material was filed on behalf of ANL in October 1989.

Overall, all of the original design requirements were met to the satisfaction of IPNS management.

\section{Acknowledgments}

This hardware was fabricated with the assistance of C. F. Konicek, J. R. Summers, F. J. Karasek, C. W. Benedict, and R. J. Blaskovitz. 


\section{References}

1. B. A. Loomis, H. R. Thresh, G. L. Fogle, and S. B. Gerber, Design, Production, and Evaluation of a Zircaloy-Clad Uranium Target for an Intense Pulsed Neutron Source Application, Nucl. Technol. 55, 617 (1981).

2. H. J. Rack, S. A. Dupree, J. F. Smugeresky, and A. H. Stark, Development of Boron Carbide-Copper Cermets, Sandia National Laboratories Report SAND-78-2317 (1979).

3. R. W. Keil, R. E. Riley, and H. Sheinberg, Feasibility Study of Fabrication of $\mathrm{Cu}-\mathrm{B} 4 \mathrm{C}$ Sheet, Los Alamos National Laboratory Report LA-3570-MS (1966).

4. J. F. Smugeresky, H. J. Pack, and G. B. Brassell, Development of a NonVolatile Boron Carbide-Copper Cermet Neutron Shield, Sandia National Laboratories Report SAND-80-0802C (1980).

5. W. K. Anderson and J. S. Theilacker, Neutron Absorber Materials for Reactor Control, Atomic Energy Commission, Washington, D.C., (1962).

6. D. K. Worn and R. E. Buttress, Control of Nuclear Reactions, U.S. Patent 3,000,802, awarded September 19, 1961.

7. R. F. Domagala, T. C. Wiencek, H. R. Thresh, and D. Stahl, The Status of Uranium-Silicon Alloy Fuel Development for the RERTR Program, in Argonne National Laboratory Report ANL/RERTR/TM-3, pp. 90-115 (1983). 
Distribution for ANL-91/44

\section{Internal}
I. H. Bresof
C. A. Malefyt (2)
R. W. Weeks
B. S. Brown
A. W. Schulke
J. M. Carpenter
W. J. Shack
D. R. Diercks
J. R. Summers
T. C. Wiencek (20)
ANL Patent Dept.
A. E. Knox
H. R. Thresh
C. F. Konicek
C. E. Till

\section{External}

DOE-OSTI for distribution per UC-413 (48)

ANL-TIS Libraries

Chicago Operations Office, DOE:

D. T. Goldman

F. Herbaty

A. L. Taboas

Materials and Components Technology Division Review Committee:

$\mathrm{H}$. Berger, Industrial Quality, Inc., Gaithersburg, MD

M. S. Dresselhaus, Massachusetts Institute of Technology, Cambridge, MA

S. J. Green, Electric Power Research Institute, Palo Alto, CA

R. A. Greenkorn, Purdue University, West Lafayette, IN

C.-Y. Li, Cornell University, Ithaca, NY

P. G. Shewmon, Ohio State University, Columbus

R. E. Smith, Electric Power Research Institute, NDE Ctr., Charlotte, NC 

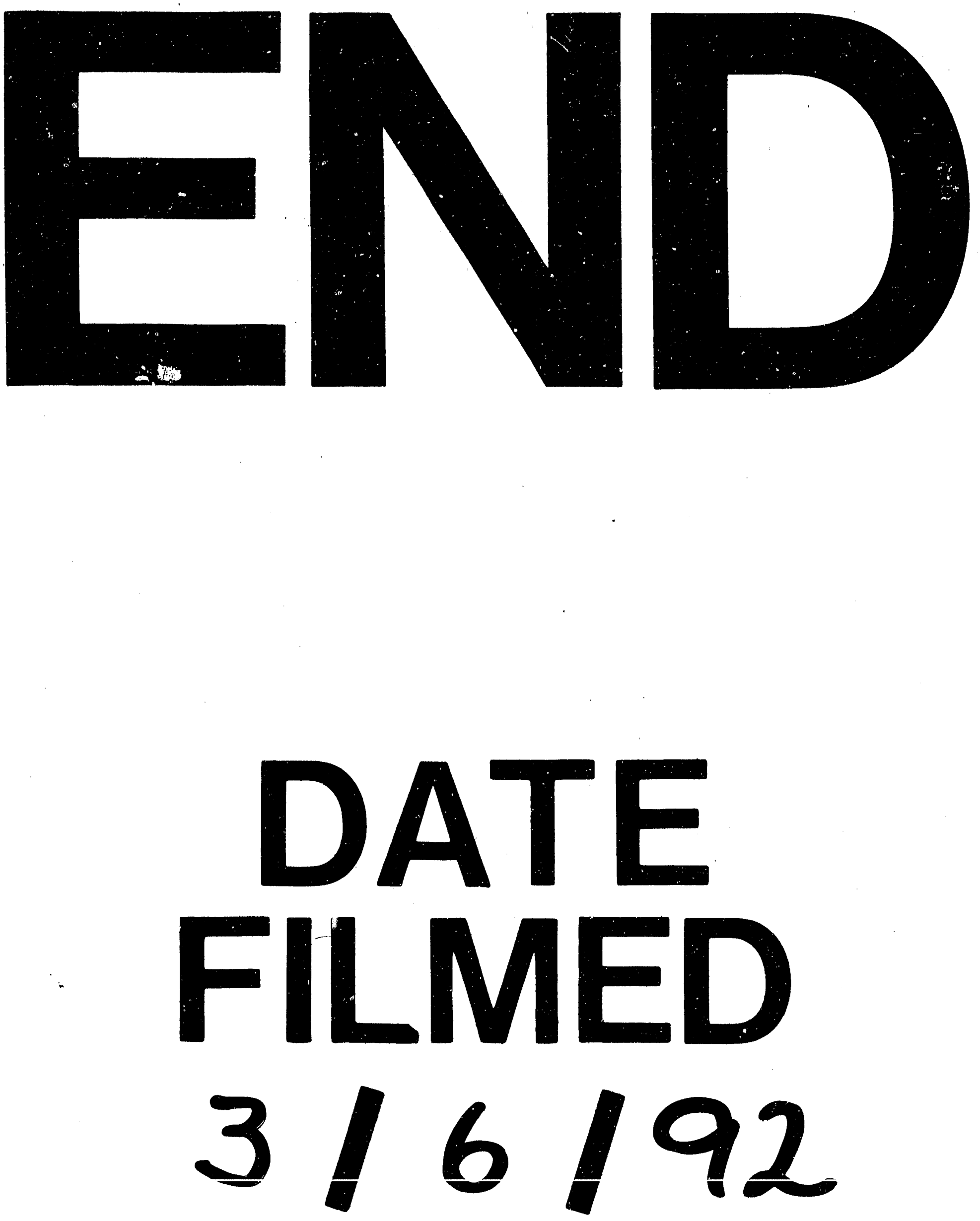
